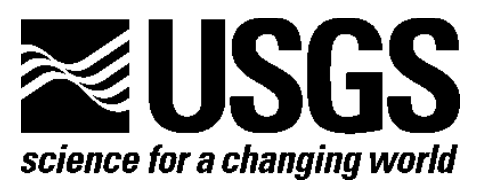

Prepared in cooperation with the U.S. Department of Defense Strategic Environmental Research and Development Program

\title{
Active Tensor Magnetic Gradiometer System Final Report for Project MM-1514
}

By David V. Smith, Jeffrey D. Phillips, and S. Raymond Hutton

Open-File Report 2013-1228 


\section{U.S. Department of the Interior \\ SALLY JEWELL, Secretary}

\section{U.S. Geological Survey \\ Suzette M. Kimball, Acting Director}

U.S. Geological Survey, Reston, Virginia: 2014

For more information on the USGS-the Federal source for science about the Earth,

its natural and living resources, natural hazards, and the environment-visit

http://www.usgs.gov or call 1-888-ASK-USGS

For an overview of USGS information products, including maps, imagery, and publications, visit $h$ ttp://www.usgs.gov/pubprod

To order this and other USGS information products, visit http://store.usgs.gov

Suggested citation:

Smith, D.V., Phillips, J.D., and Hutton, S.R., 2014, Active tensor magnetic gradiometer system final report for Project MM-1514: U.S. Geological Survey Open-File Report 2013-1228, 39 p., http://dx.doi.org/10.3133/ofr20131228.

Any use of trade, firm, or product names is for descriptive purposes only and does not imply endorsement by the U.S. Government.

Although this information product, for the most part, is in the public domain, it also may contain copyrighted materials as noted in the text. Permission to reproduce copyrighted items must be secured from the copyright owner.

ISSN 2331-1258 (online) 


\section{Contents}

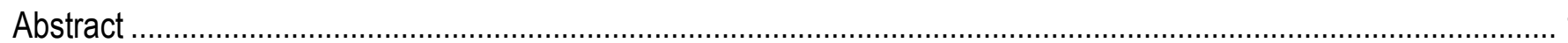

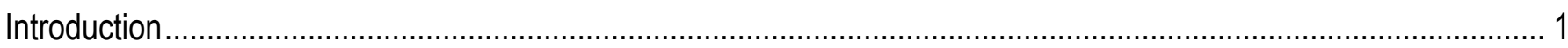

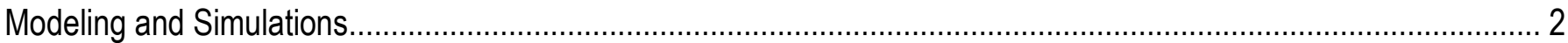

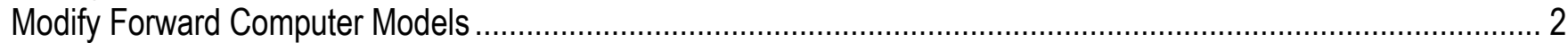

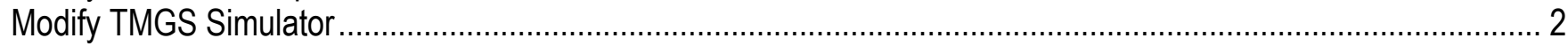

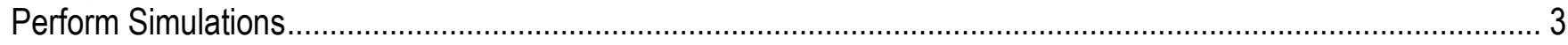

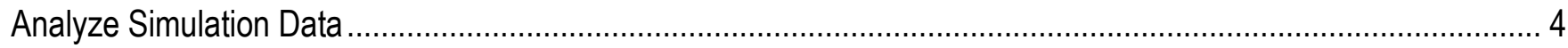

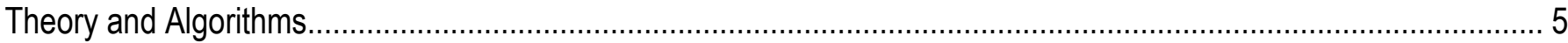

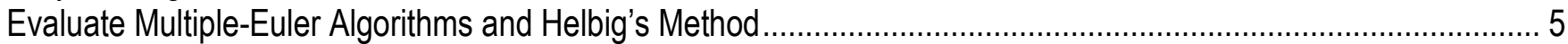

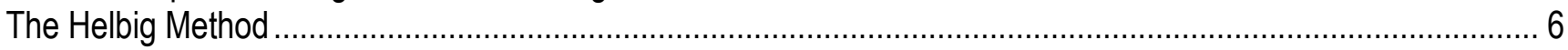

Extending the Helbig Method to Magnetic Gradient Measurements............................................................. 7

The Euler Equation.................................................................................................................10

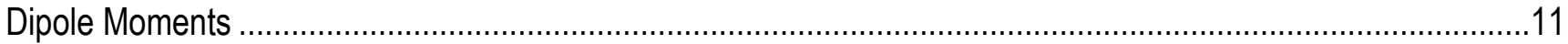

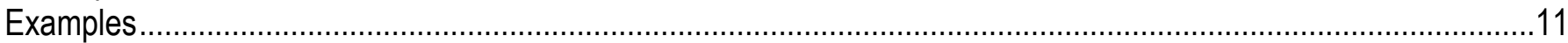

Example 1 - Using (Noise-Free) Magnetic Field Components ........................................................................11

Example 2 - Using (Noise-Free) Tensor Magnetic Gradient Components ..........................................................11

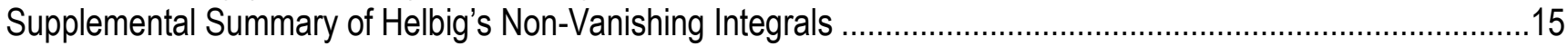

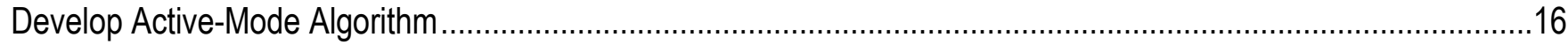

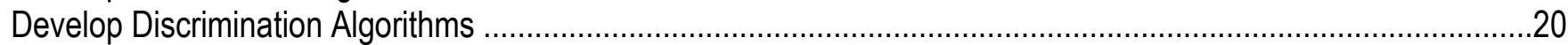

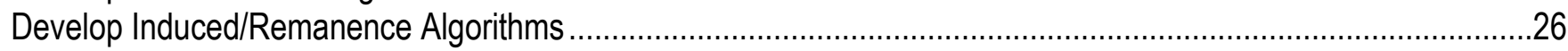

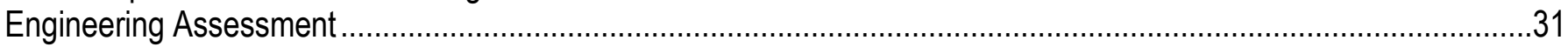

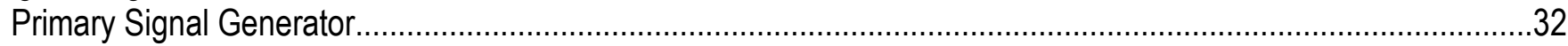

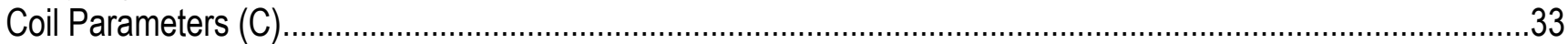

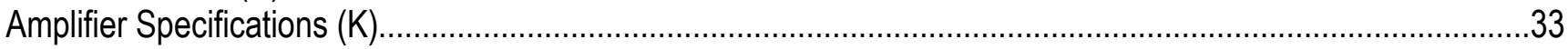

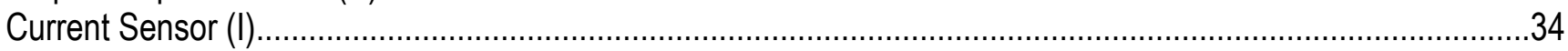

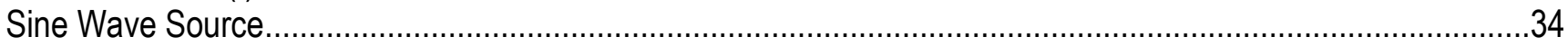

Temperature Control (T) ..............................................................................................................

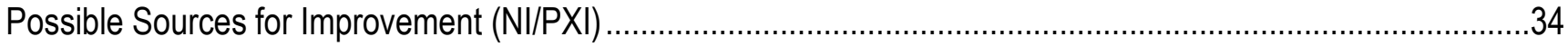

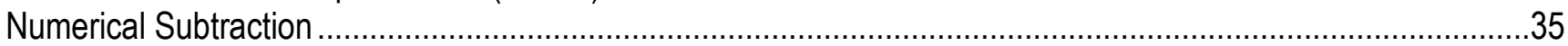

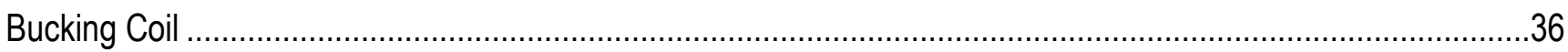

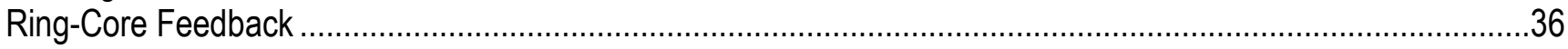

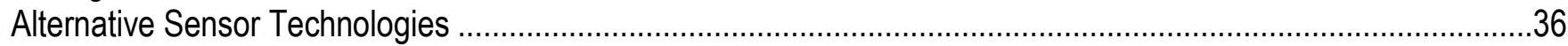

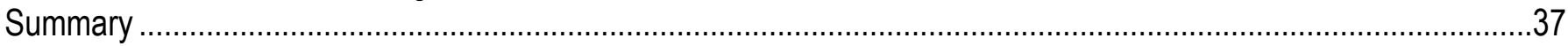

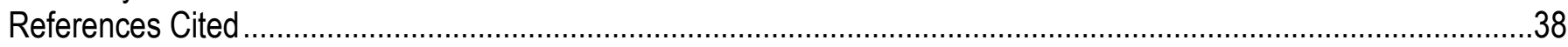

\section{Figures}

Figure 1. Screen capture of example graphical user interface of a simulation run. Interactive controls are in the left panel. The targets and array trajectory are displayed in the right panel......................................................... 4

Figure 2. Data flow diagram for Active Tensor Magnetic Gradiometer System (ATMGS) data processing and analysis......

Figure 3. (A) $X$ (north), $Y$ (east), and $Z$ (vertical) magnetic field components produced by the three test dipoles of table 1. Circles indicate the dipole locations. (B) Magnetic field components produced by the solution dipoles of table 2 
Figure 4. (A) Five independent components of the magnetic gradient tensor for the three test dipoles of table 1. Circles indicate the dipole locations. (B) Magnetic gradient tensor components produced by the solution dipoles of table 3

Figure 5. Simulated data waveforms for four $20-\mathrm{mm}$ spheres buried $0.02 \mathrm{~m}$ deep along a single line. The four spheres have the same magnetic permeability but different remanent magnetization (increasing from left to right). The top plot shows the z-component of head 1. Separation of the active signal (blue) from the static signal (purple) is achieved by simple high-pass and low-pass filtering, respectively. The inductive response for the four spheres is identical, but the static magnetic anomaly (bottom plot) from each differs according to their magnetic moments... 17 Figure 6. Example of simulated data along line over three $60-\mathrm{mm}$ targets in the standard model. Shown are the received signal from head $1 \mathrm{z}$-component (red), the static signal (green), the active signal (blue) and the rectified (magenta) and demodulated signal (gray)

Figure 7. Active tensor magnetic gradiometer system output. Close up of simulation data over a single 60-mm target in the standard model. Shown are the received signal from head 1 z-component (red), the static signal (purple), the active signal (blue) and the rectified (magenta) and demodulated signal (gray).................................. 18

Figure 8. Map of head1 z-component only of static anomalies of six 60-mm targets in the standard model ......... 19

Figure 9. Demodulated (envelope) active component of six isolated $60-\mathrm{mm}$ targets in the standard model.......... 20

Figure 10. Map of maxima/minima of active component selected for inversion to induced moments. The locations of different magnetic z-components (red, magenta, yellow, blue) are offset because of the physical separation of the fluxgate heads on the array. The lines are irregular because of terrain effects.

Figure 11. Recovered moments $\left(M_{s}\right)$ versus actual induced moments $\left(M_{i}\right)$. True moment values are slightly greater in magnitude than the moments recovered through inversion .............................................................. 23

Figure 12. Effects of noise sources on recovered moments. Solid diamond is noise free; hollow blue square is with system noise; yellow triangle is with terrain effects; and red square is with both noise and terrain effects .....

Figure 13. Recovered spheroid dimensions for modeled spheroids. Scenario 1 and scenario 10 represent the 60-mm spheroid. Scenarios 1-5 are increasingly prolate, whereas scenarios 6-9 are increasingly oblate.

Scenarios 1-9 are solutions based on primary field maxima, and scenarios 10-18 are from primary field minima .... 25

Figure 14. Histograms of length-to-diameter ratios. The ratio of length to diameter is diagnostic of whether a

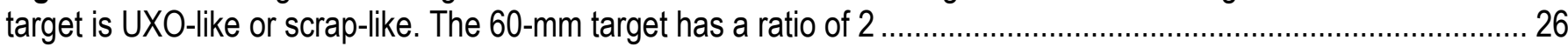

Figure 15. Conceptual block diagram of the Active Tensor Magnetic Gradiometer System (ATMGS) ................ 32 Figure 16. Conceptual block diagram of the active drive unit. Functions controlled by the control unit are listed in the NI/PXI box. Subsystems are labeled NI/PXI, K, I, C, and T

Figure 17. Primary coil field strength with distance in relation to the sensor array. The black rectangle represents the array baseplate; the white rectangles represent fluxgate heads. Magnetic field strength is plotted for a 1.0-m diameter coil (red) and a 1.5-m diameter coil (blue). Arrows point to the field strength and gradient at the location of the z-component fluxgate axes.

\section{Tables}

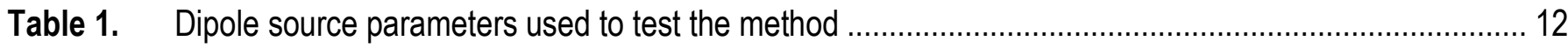

Table 2. Results of inversion using the magnetic field components............................................................ 12

Table 3. Results of inversion using the tensor magnetic gradient component ............................................... 12

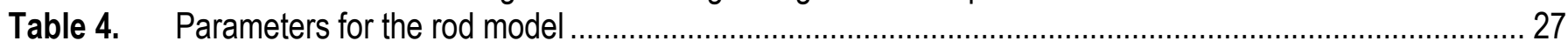

Table 5. Results of Helbig-Euler inversion on the rod model without any inducing field .................................. 27

Table 6. Results of Helbig-Euler inversion on the rod model with downward-inducing field ............................... 28

Table 7. Results of Helbig-Euler inversion on the rod model with upward-inducing field ...................................28

Table 8. Estimated magnetic susceptibilities and Koenigsberger ratios for the rod model ................................29

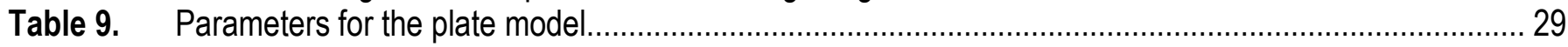

Table 10. Results of Helbig-Euler inversion on the plate model without any inducing field................................ 30

Table 11. Results of Helbig-Euler inversion on the plate model with downward-inducing field ............................30 
Table 12. Results of Helbig-Euler inversion on the plate model with upward-inducing field

Table 13. Estimated magnetic susceptibilities and Koenigsberger ratios for the plate model.

\section{Conversion Factors}

SI to Inch/Pound

\begin{tabular}{lll}
\hline \multicolumn{1}{c}{ Multiply } & By & To obtain \\
\hline \multicolumn{3}{c}{ Length } \\
\hline centimeter $(\mathrm{cm})$ & 0.3937 & inch (in.) \\
millimeter (mm) & 0.03937 & inch (in.) \\
meter $(\mathrm{m})$ & 3.281 & foot (ft) \\
\hline
\end{tabular}

Temperature in degrees Celsius $\left({ }^{\circ} \mathrm{C}\right)$ may be converted to degrees Fahrenheit $\left({ }^{\circ} \mathrm{F}\right)$ as follows: ${ }^{\circ} \mathrm{F}=\left(1.8 x^{\circ} \mathrm{C}\right)+32$ 


\title{
Active Tensor Magnetic Gradiometer System Final Report for Project MM-1514
}

\author{
By David V. Smith, Jeffrey D. Phillips, and S. Raymond Hutton
}

\begin{abstract}
An interactive computer simulation program, based on physical models of system sensors, platform geometry, Earth environment, and spheroidal magnetically-permeable targets, was developed to generate synthetic magnetic field data from a conceptual tensor magnetic gradiometer system equipped with an active primary field generator. The system sensors emulate the prototype tensor magnetic gradiometer system (TMGS) developed under a separate contract for unexploded ordnance (UXO) detection and classification. Time-series data from different simulation scenarios were analyzed to recover physical dimensions of the target source. Helbig-Euler simulations were run with rectangular and rod-like source bodies to determine whether such a system could separate the induced component of the magnetization from the remanent component for each target. This report concludes with an engineering assessment of a practical system design.
\end{abstract}

\section{Introduction}

The objective of the Active Tensor Magnetic Gradiometer research project, which was conducted by the U.S. Geological Survey (USGS) in cooperation with the Strategic Environmental Research and Development Program (SERDP), was to prove the concept of an active tensor magnetic gradiometer system outcomes of this feasibility study were identified as (1) a conceptual design at a functional system block diagram level, containing specific engineering design and operational parameters, and (2) a theoretical framework for analyzing and interpreting system data. Conceptual designs for an active magnetic gradient measurement system are based upon the existing tensor magnetic gradiometer system (TMGS) developed under project MM-1328 entitled, "Evaluation, Modification, and Testing of the Very Early Time Electromagnetic (VETEM) System, the High Frequency Sounder (HFS), and the Tensor Magnetic Gradiometer System (TMGS) for UXO Detection, Imaging, and Discrimination.” The TMGS developed under MM-1328 was successfully tested at the Standardized Test Site at Yuma Proving Ground, Arizona, in 2005 over the Calibration Grid, a small test area seeded with inert ordnance and clutter. By modifying the prototype TMGS with an active magnetic source UXO surveys can be performed in two modes simultaneously - passive and active. In the passive mode, tensor data will be acquired for all target and natural anomalies over an area. At the same time, tensor data will be acquired for an alternating magnetic field at a precisely driven frequency. In this active mode, data will be acquired only for targets in the near zone of the field generator. Active mode data can be used to identify the target's remanent magnetization. By simultaneously measuring static anomalies in a search area and active anomalies in closer proximity to the instrument, this approach has the potential to segregate UXO and clutter. By separating a target's remanent and induced magnetization, discrimination of UXOlike targets and scrap-like clutter can be improved (Billings, 2002). 
Three distinct but related methods were used in this feasibility study. First, numerical computer models and simulations of various possible configurations of an ATMGS were developed and implemented. Simulation data were used as the basis for developing data processing and analysis routines. Second, theoretical approaches to analyzing ATMGS data were investigated. Third, engineering analyses were undertaken of sensors and interface electronics to determine those modifications necessary to implement a prototype ATMGS.

\section{Modeling and Simulations}

\section{Modify Forward Computer Models}

Because no instrumentation development or empirical experiments were proposed, a successful outcome depended on a realistic simulation of the TMGS with an active source. The ATMGS simulator was built upon the TMGS simulator already developed using Interactive Data Language (IDL) because it has all the necessary features, which are

- Platform geometry: wheelbase, wheel diameter, array location and height, global positioning system (GPS) location and height;

- Array geometry: sensor geometry and baseline separation;

- Sensor properties: axis offsets, inorthogonalities, noise;

- System properties: sample rate, channel gains, noise;

- Site size: variable dimensions;

- Irregular (fractal) terrain model of relief;

- Ground magnetization (natural anomalies as a vector field);

- Earth's main magnetic field model with diurnal variation;

- Platform trajectory: variable line spacing with interactive speed and steering controls;

- Targets: location, depth, magnetization vector; and

- Outputs: 12 vector components, 5 measured gradients, 6 true gradients, true total magnetic field at centroid of array, roll, pitch, fluxgate sensor location (x, y, z of each axis), array location (x, $\mathrm{y}, \mathrm{z}$ of centroid), GPS location ( $\mathrm{x}, \mathrm{y}, \mathrm{z}$ ), and time base.

Relevant parameters of the simulation-12 vector components, roll, pitch, fluxgate sensor location ( $\mathrm{x}, \mathrm{y}, \mathrm{z}$ of each of 12 axes), array location (x, y, z of centroid), and time base-were used in the forward model that calculates the secondary field caused by a target at each of the 12 sensor locations.

Limitations and assumptions include that inorthogonalities of the sensor axes in the array reference frame are taken as zero and that the magnetic field values were not converted to the binnumber/error-voltage format of the real TMGS. We made the assumption that empirically measured calibration coefficients for the real system are sufficiently accurate to orthogonalize the axes and to convert from raw voltages to magnetic field magnitudes.

\section{Modify TMGS Simulator}

The original simulator was modified to include several software modules:

- Targets as spheroids: location (x, y, z), length (radius $a$ ), diameter (radius $c$ ), azimuth and dip of radius $a$, and magnetic permeability;

- Primary field generator (solenoid): coil diameter, height, wire gauge, number of turns, current, frequency; 
- Primary field at target location: magnetic field components $\left(\mathrm{B}_{\mathrm{x}}, \mathrm{By}, \mathrm{Bz}\right)$ calculated at target location using Biot-Savart law for the modeled solenoid; and

- Spheroidal induction: magnetization vectors $\left(\mathrm{M}_{\mathrm{x}}, \mathrm{M}_{\mathrm{y}}, \mathrm{M}_{\mathrm{z}}\right)$ of a spheroid with radii $a$ and $c$ and azimuth and dip of radius $a$ in an external magnetic field $\left(\mathrm{B}_{\mathrm{x}}, \mathrm{B}_{\mathrm{y}}, \mathrm{B}_{\mathrm{z}}\right)$.

We made the assumption that the magnetic field at the spheroidal target's centroid is uniform over volume of target. This assumption is valid for small spheroids at distances approximately the diameter of the solenoid but does not hold for closer targets or large spheroids. We assume the error in our simulations is negligible, although we offer no proof. This assumption was made to avoid the computational complexity and demands of an arbitrary spheroid in a nonuniform magnetic field. We also assume that, for typical UXO bodies, the total magnetization of a solid spheroid model is close to (within 10 percent) that of a spheroidal shell model (Billings, 2002; Butler, 2001; Altshuler, 1996). Again, this assumption was made to avoid increased computational complexity.

\section{Perform Simulations}

The simulator can perform an unlimited number of scenarios with varied targets and terrains. This research concentrated on a very limited set of scenarios in order to develop and investigate data processing, analysis, and interpretation techniques. The following parameters constituted the standard scenario:

- Site dimensions: 10 x 10 meters (m);

- Trajectory: 0.25-m line spacing, traveling south-to-north at 2 meters per second $(\mathrm{m} / \mathrm{s})$;

- Targets: six 60-mm spheroids at $0.2 \mathrm{~m}$ depth, equally spaced;

- Target orientations: three at 0 azimuth and 0,30,60 degrees dip; three at 90 azimuth and 0, 30, 60 degrees dip; and

- Terrain: fractal surface with $+/-10 \mathrm{~cm}$ relief.

The following parameters modeled the ATMGS system:

- Planar cross array with paired magnetic component baselines of 35.36, 45.96, and $52.56 \mathrm{~cm}$;

- Towed platform with dimensions of the cart used for tests at Yuma Proving Ground;

- Sample rate: 900 hertz $(\mathrm{Hz})$; and

- Sensor noise: $16 \mathrm{pT} / \mathrm{Hz}^{1 / 2}$.

A graphical representation of a non-standard simulation run with 11 targets is shown in figure 1, where the targets are shown in red and the trajectory of the array is shown in green. The trajectory is irregular because of terrain effects. 


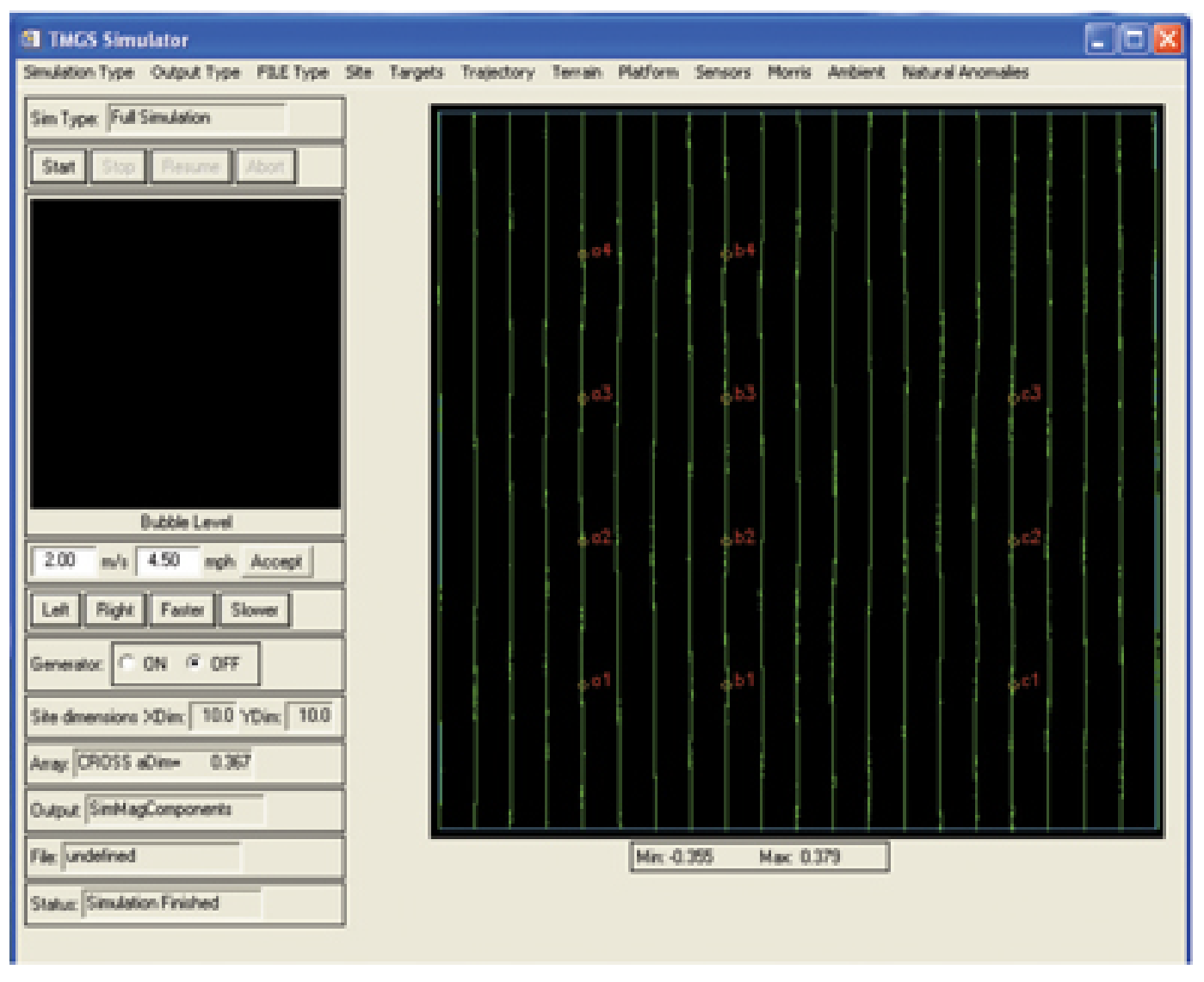

Figure 1. Screen capture of example graphical user interface of a simulation run. Interactive controls are in the left panel. The targets and array trajectory are displayed in the right panel.

\section{Analyze Simulation Data}

Data files generated by the simulations were processed in Geosoft's Oasis montaj. This software has the capability of handling extremely large data sets efficiently and contains tools for filtering, gridding and displaying time-series and spatial data. Oasis montaj was used to generate data sets containing position $(\mathrm{x}, \mathrm{y}, \mathrm{z})$ and measured gradients $\left(\mathrm{G}_{\mathrm{ij}}\right)$. USGS software was used to determine target location using Euler and Helbig analyses. IDL programs were used to calculate induced moments $\left(\mathrm{M}_{\mathrm{x}}, \mathrm{M}_{\mathrm{y}}, \mathrm{M}_{\mathrm{z}}\right)$ at each location where the primary field was at a minimum or maximum. The maxima and minima were selected because the rate of change of the magnetic field with time $(\mathrm{dB} / \mathrm{dt})$ is zero at these points. Therefore, magnetostatic equations can be applied. Knowing the location of the primary field generator, the array centroid, and the target, we made estimates of the target's spheroidal geometry based upon the spatial variation of the induced magnetic moments. The data flow diagram is given in figure 2 . 


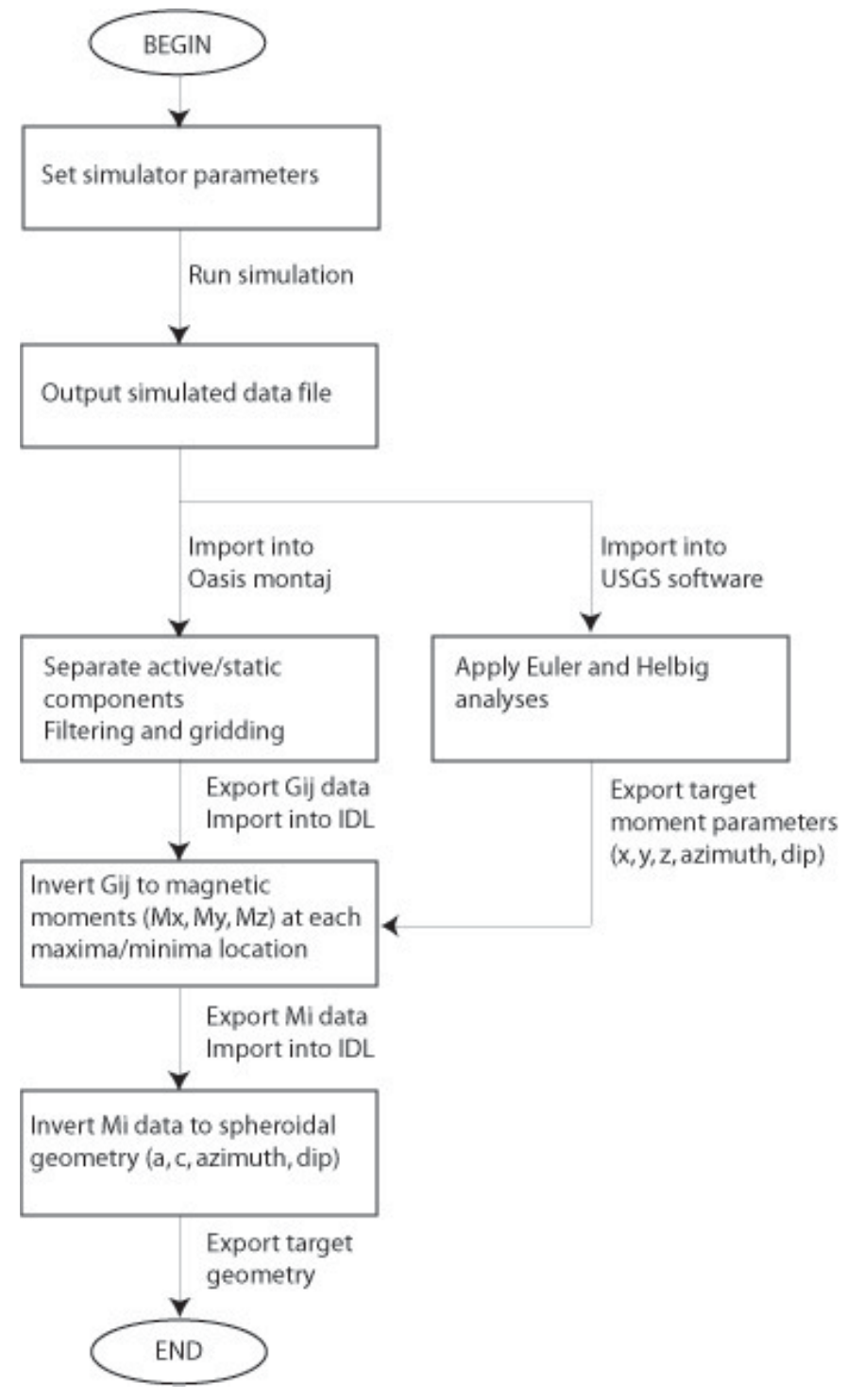

Figure 2. Data flow diagram for Active Tensor Magnetic Gradiometer System (ATMGS) data processing and analysis.

\section{Theory and Algorithms}

\section{Evaluate Multiple-Euler Algorithms and Helbig's Method}

Although Euler and Werner multiple-source algorithms have proven useful for locating UXO sources, they provide no additional physical property information about the sources. To determine the magnetic dipole moments and the magnetization (or elongation) directions of the sources, another approach is required. A first step we investigated involved implementing Helbig's method (Helbig, 1963), which uses the first moments of magnetic vector components to estimate total magnetization directions. By using Helbig's method to estimate the total magnetization 
directions at the Euler source locations for each of the dual-mode data sets, it should be possible to separate the induced component of the magnetization from the remanent component for each source. Using the estimated source locations and the estimated magnetization directions, we can perform a linear inversion to estimate the magnetic susceptibility, the remanent magnetization, and the magnetic dipole moments of the sources.

Helbig's method has been successfully applied to geological problems (Schmidt and Clark, 1997, 1998) and has been implemented by the USGS for total-field magnetic data (Phillips, 2005; Phillips and others, 2007). It works best on dipole sources that have adequate horizontal separation for the first moments to be reliably estimated. Application of Helbig's method to the passive mode data of the tensor survey should be straightforward, providing estimates of total magnetization directions and magnetic dipole moments for the sources. Application to the active mode data should allow separation of the total magnetization into induced and remanent components but will involve the complication that the inducing field direction varies over the source distribution.

The total magnetization of a magnetic source is the vector sum of the remanent magnetization and the induced magnetization. The Helbig method, as implemented by Phillips (2005), is useful for estimating the horizontal positions and the total magnetization directions of compact magnetic sources from measured or calculated magnetic vector field components.

In the following exposition (Phillips and others, 2007), we extend the Helbig method in several ways. First, we show how the method can be modified so that magnetic gradient tensor measurements can be used instead of magnetic vector component measurements. Next, we show how, given the horizontal positions of the sources, a simplified version of the Euler equation, applied in windows, can be used to estimate the depths to the compact sources under the assumption that they are magnetic dipoles. Finally, we show how a linear least-squares fit to the data can be used to determine the dipole moments of the sources.

This extended Helbig approach can be used to locate and characterize compact magnetic sources such as ore bodies, UXO, and abandoned wells. It may also prove useful for removing some cultural noise, such as strong, localized anomalies produced by steel buildings, from aeromagnetic data.

The Helbig Method

In the Helbig method (Helbig, 1963; Schmidt and Clark, 1997, 1998; Phillips, 2005), the first moments of vector magnetic field components are used to estimate the direction of the total magnetization. The magnetic field components can be derived from total-field magnetic data using Fourier filters.

Using the Helbig integrals, total magnetization directions can be estimated in small data windows centered on each grid node of the magnetic vector field component grids. If the central grid node lies over a compact source that can be represented by a magnetic dipole, then the calculated magnetization direction will accurately predict the total magnetization direction of the dipole, and the direction will remain relatively constant as the window size is increased in small steps. On the other hand, if the central grid node does not lie over a source, the calculated total magnetization direction will change with increasing window size.

We can locate the grid nodes where the estimated magnetization direction is relatively insensitive to window size by setting a threshold for the maximum allowable angular change in the direction between successive window sizes, then counting the number of successive window sizes that produce solutions with angular changes below this threshold. Grid nodes with large counts identify source locations; those with small counts identify source-free areas. With this approach, 
the Helbig method can be used to estimate the horizontal positions of the compact sources as well as their total magnetization directions.

By averaging the magnetization directions for the solutions that fall below the threshold, we get an estimate of the total magnetization direction at each grid node. This estimate will be accurate only at grid nodes that lie over sources, that is, those with large counts. However, between sources the estimated magnetization directions will be continuous. This means that the Helbig method can also be used to produce a continuous estimate of the magnetization direction over a magnetic survey area, which can then be sampled at source locations determined using a second method, such as Euler deconvolution (Reid and others, 1990).

The Helbig method is based on the observation (Helbig, 1963) that the vector components $\left(m_{x}, m_{y}, m_{z}\right)$ of the total magnetization of a compact source can be estimated from the first moments of the vector components $\left(B_{x}, B_{y}, B_{z}\right)$ of the anomalous magnetic field produced by the source. Here we use the convention of geomagnetism that the $x$-axis points north, the $y$-axis points east, and the $z$-axis points down. The first moments are evaluated as infinite integrals over the horizontal plane.

$$
\begin{aligned}
& m_{x}=-\frac{1}{2 \pi} \int_{-\infty}^{\infty} \int_{-\infty}^{\infty} x B_{z}(x, y) d x d y \\
& m_{y}=-\frac{1}{2 \pi} \int_{-\infty}^{\infty} \int_{-\infty}^{\infty} y B_{z}(x, y) d x d y \\
& m_{z}=-\frac{1}{2 \pi} \int_{-\infty}^{\infty} \int_{-\infty}^{\infty} x B_{x}(x, y) d x d y=-\frac{1}{2 \pi} \int_{-\infty}^{\infty} \int_{-\infty}^{\infty} y B_{y}(x, y) d x d y
\end{aligned}
$$

The other two first moments are zero, as are the integrals (mean values) of $B_{x}, B_{y}$, and $B_{z}$ over the plane. We refer to these five integrals as Helbig's vanishing integrals.

Phillips (2005) has shown that, in order to estimate total magnetization directions using the integrals of equation set (1) within a finite data window, it is necessary to satisfy Helbig's vanishing integrals within the finite window by removing a planar surface from the magnetic vector component within the window. This assures that the mean values of the components are zero within the window and that the vanishing moments are approximately zero.

\section{Extending the Helbig Method to Magnetic Gradient Measurements}

This requirement to estimate and remove planar surfaces from each magnetic vector component in the finite data window, while computationally straightforward, does represent a burden when many overlapping data windows of different sizes are used in the analysis. In an attempt to relax this requirement, we can consider using first- or second-order derivatives of the magnetic vector components for Helbig analysis. First-order derivatives of the components are measured directly by tensor magnetic gradiometer systems, such as those currently being evaluated for application to the detection of UXO and for commercial mineral exploration.

To develop Helbig equations for derivatives of the magnetic vector components, we can use integration-by-parts on the integrals of equation set 1 . For example, the $m_{x}$ component can be expressed as either 


$$
\begin{aligned}
m_{x} & =-\frac{1}{2 \pi} \int_{-\infty}^{\infty} \int_{-\infty}^{\infty} x B_{z}(x, y) d x d y \\
& =-\frac{1}{2 \pi} \int_{-\infty}^{\infty}\left[\int_{-\infty}^{\infty} B_{z}(x, y) x d x\right] d y \\
& =-\frac{1}{2 \pi} \int_{-\infty}^{\infty}\left[\left.B_{z}(x, y) \frac{x^{2}}{2}\right|_{-\infty} ^{\infty}-\int_{-\infty}^{\infty} \frac{x^{2}}{2} \frac{\partial B_{z}}{\partial x} d x\right] d y
\end{aligned}
$$

or

$$
\begin{aligned}
m_{x} & =-\frac{1}{2 \pi} \int_{-\infty-\infty}^{\infty} \int_{-\infty}^{\infty} x B_{z}(x, y) d x d y \\
& =-\frac{1}{2 \pi} \int_{-\infty}^{\infty}\left[\int_{-\infty}^{\infty} B_{z}(x, y) x d y\right] d x \\
& =-\frac{1}{2 \pi} \int_{-\infty}^{\infty}\left[\left.B_{z}(x, y) x y\right|_{-\infty} ^{\infty}-\int_{-\infty}^{\infty} x y \frac{\partial B_{z}}{\partial y} d y\right] d x
\end{aligned}
$$

If the vertical component $B_{z}$ of the magnetic field decays more rapidly than the square of the distance, which is the case for all compact magnetic sources, then the first terms in the square brackets are zero. It follows that equation set 1 can be rewritten in terms of second moments of first derivatives of the magnetic vector components as

$$
\begin{aligned}
m_{x} & =\frac{1}{4 \pi} \int_{-\infty}^{\infty} \int_{-\infty}^{\infty} x^{2} \frac{\partial B_{z}}{\partial x} d x d y=\frac{1}{2 \pi} \int_{-\infty}^{\infty} \int_{-\infty}^{\infty} x y \frac{\partial B_{z}}{\partial y} d x d y \\
m_{y} & =\frac{1}{4 \pi} \int_{-\infty}^{\infty} \int_{-\infty}^{\infty} y^{2} \frac{\partial B_{z}}{\partial y} d x d y=\frac{1}{2 \pi} \int_{-\infty}^{\infty} \int_{-\infty}^{\infty} x y \frac{\partial B_{z}}{\partial x} d x d y \\
m_{z} & =\frac{1}{4 \pi} \int_{-\infty}^{\infty} \int_{-\infty}^{\infty} x^{2} \frac{\partial B_{x}}{\partial x} d x d y=\frac{1}{4 \pi} \int_{-\infty}^{\infty} \int_{-\infty}^{\infty} y^{2} \frac{\partial B_{y}}{\partial y} d x d y \\
& =\frac{1}{2 \pi} \int_{-\infty}^{\infty} \int_{-\infty}^{\infty} x y \frac{\partial B_{x}}{\partial y} d x d y=\frac{1}{2 \pi} \int_{-\infty}^{\infty} \int_{-\infty}^{\infty} x y \frac{\partial B_{y}}{\partial x} d x d y
\end{aligned}
$$

The partial derivatives represent components that can be directly measured with a tensor magnetic gradient system. In terms of standard symmetric tensor notation,

$$
\frac{\partial B_{x}}{\partial x}=B_{x x}, \frac{\partial B_{y}}{\partial y}=B_{y y}, \frac{\partial B_{x}}{\partial y}=\frac{\partial B_{y}}{\partial x}=B_{x y}=B_{y x}, \frac{\partial B_{z}}{\partial x}=B_{z x}=B_{x z}, \frac{\partial B_{z}}{\partial y}=B_{z y}=B_{y z}
$$

In addition to being useful for tensor magnetic gradient measurements, equation set 4 has the advantage over equation set 1 that, in order to evaluate the integrals within finite data windows and still satisfy Helbig's vanishing integrals, it is necessary to remove only the mean value from each tensor component within the window. 
Because equation set 4 provides at least two estimates for each magnetization component, it allows for some measure of the reliability of each component. For example, the two estimates of $m_{x}$ can be combined into a mean value and an uncertainty in the mean as

$$
\hat{m}_{x}=\frac{1}{2}\left(\hat{m}_{x 1}+\hat{m}_{x 2}\right) \pm \frac{1}{2}\left(\hat{m}_{x 1}-\hat{m}_{x 2}\right)
$$

This is an improvement over equation set 1 , which only provides a measure of the uncertainty in the $m_{z}$ component.

When the magnetization components are estimated in a finite window, it turns out that the two estimates of $m_{x}$ are not strictly equivalent. Instead, there are two sets of components, one from the integrals starting with $1 / 2 \pi$ and one from the integrals starting with $1 / 4 \pi$. The two sets produce magnetization vectors with identical directions but slightly different magnitudes. Details are given in the section, "Supplemental Summary of Helbig's Non-Vanishing Integrals".

Starting from equation set 4 , the integration-by-parts can be repeated to generate a third set of equations for the magnetization components, this time in terms of third moments of second derivatives of the vector components.

$$
\begin{aligned}
m_{x} & =-\frac{1}{12 \pi} \int_{-\infty}^{\infty} \int_{-\infty}^{\infty} x^{3} \frac{\partial^{2} B_{z}}{\partial x^{2}} d x d y=-\frac{1}{4 \pi} \int_{-\infty}^{\infty} \int_{-\infty}^{\infty} x^{2} y \frac{\partial^{2} B_{z}}{\partial x \partial y} d x d y \\
& =-\frac{1}{4 \pi} \int_{-\infty}^{\infty} \int_{-\infty}^{\infty} x y^{2} \frac{\partial^{2} B_{z}}{\partial y^{2}} d x d y \\
m_{y} & =-\frac{1}{12 \pi} \int_{-\infty}^{\infty} \int_{-\infty}^{\infty} y^{3} \frac{\partial^{2} B_{z}}{\partial y^{2}} d x d y=-\frac{1}{4 \pi} \int_{-\infty}^{\infty} \int_{-\infty}^{\infty} x y^{2} \frac{\partial^{2} B_{z}}{\partial x \partial y} d x d y \\
& =-\frac{1}{4 \pi} \int_{-\infty}^{\infty} \int_{-\infty}^{\infty} x^{2} y \frac{\partial^{2} B_{z}}{\partial x^{2}} d x d y \\
m_{z} & =-\frac{1}{12 \pi} \int_{-\infty}^{\infty} \int_{-\infty}^{\infty} x^{3} \frac{\partial^{2} B_{x}}{\partial x^{2}} d x d y=-\frac{1}{12 \pi} \int_{-\infty}^{\infty} \int_{-\infty}^{\infty} y^{3} \frac{\partial^{2} B_{y}}{\partial y^{2}} d x d y \\
& =-\frac{1}{4 \pi} \int_{-\infty}^{\infty} \int_{-\infty}^{\infty} x^{2} y \frac{\partial^{2} B_{x}}{\partial x \partial y} d x d y=-\frac{1}{4 \pi} \int_{-\infty}^{\infty} \int_{-\infty}^{\infty} x y^{2} \frac{\partial^{2} B_{y}}{\partial x \partial y} d x d y \\
& =-\frac{1}{4 \pi} \int_{-\infty}^{\infty} \int_{-\infty}^{\infty} x^{2} y \frac{\partial^{2} B_{y}}{\partial x^{2}} d x d y=-\frac{1}{4 \pi} \int_{-\infty}^{\infty} \int_{-\infty}^{\infty} x y^{2} \frac{\partial^{2} B_{x}}{\partial y^{2}} d x d y
\end{aligned}
$$

The second derivative terms cannot be measured directly, but they can be calculated from the vector components or from the tensor magnetic gradient components. The integrals can be evaluated in finite data windows without removing any surfaces or constants from the second derivative terms.

As with the first derivative case, components estimated using a finite window fall into multiple sets. One set of components is estimated from the integrals starting with $1 / 2 \pi$, one from the integrals starting with $1 / 4 \pi$, and one from the integrals starting with $1 / 12 \pi$. The three sets produce magnetization vectors with identical directions but slightly different magnitudes. Details are given in a later section, "Supplemental Summary of Helbig's Non-Vanishing Integrals". 


\section{The Euler Equation}

In the previous section, we showed how the Helbig method can be extended to work with tensor magnetic gradient components instead of vector magnetic field components. In either case, the Helbig method can provide estimates of the horizontal source locations and total magnetization directions of the compact sources. To fully characterize the sources, their depths and magnetic moments must be estimated.

If the horizontal locations $\left(x_{0}, y_{0}\right)$ of a dipole source are known, the Euler equation (Reid and others, 1990) can be used to estimate the depth $z_{0}$ of the dipole and a constant $\beta$ representing interference from adjacent sources.

$$
z_{0} \frac{\partial T}{\partial z}+\beta=\left(x-x_{0}\right) \frac{\partial T}{\partial x}+\left(y-y_{0}\right) \frac{\partial T}{\partial y}+n T
$$

Here $n=3$ for a dipole source and $T$ is the total field anomaly. This equation can be solved in the least-squares sense using data in small windows $(3 \times 3,5 \times 5,7 \times 7, \ldots)$ centered on the known horizontal location of each dipole source. The solution that produces the shallowest $z_{0}$ is probably the best.

An alternative approach would involve solutions using the vector components $\left(B_{x}, B_{y}, B_{z}\right)$ computed for the Helbig method and the magnetic potential $(V)$ computed as the negative of the first vertical integral of $B_{z}$ :

$$
z_{0} B_{z}+\beta=\left(x-x_{0}\right) B_{x}+\left(y-y_{0}\right) B_{y}+n V
$$

In this case, $n=2$ for a dipole source.

For the case of magnetic gradient tensor measurements or calculated derivatives of vector components, there are three Euler equations (Zhang and others, 2000):

$$
\begin{aligned}
& z_{0} B_{z z}+\beta_{z}=\left(x-x_{0}\right) B_{z x}+\left(y-y_{0}\right) B_{z y}+n B_{z} \\
& z_{0} B_{x z}+\beta_{x}=\left(x-x_{0}\right) B_{x x}+\left(y-y_{0}\right) B_{x y}+n B_{x} \\
& z_{0} B_{y z}+\beta_{y}=\left(x-x_{0}\right) B_{y x}+\left(y-y_{0}\right) B_{y y}+n B_{y}
\end{aligned}
$$

or, equivalently

$$
\begin{aligned}
& z_{0} \frac{\partial B_{z}}{\partial z}+\beta_{z}=\left(x-x_{0}\right) \frac{\partial B_{z}}{\partial x}+\left(y-y_{0}\right) \frac{\partial B_{z}}{\partial y}+n B_{z} \\
& z_{0} \frac{\partial B_{x}}{\partial z}+\beta_{x}=\left(x-x_{0}\right) \frac{\partial B_{x}}{\partial x}+\left(y-y_{0}\right) \frac{\partial B_{x}}{\partial y}+n B_{x} \\
& z_{0} \frac{\partial B_{y}}{\partial z}+\beta_{y}=\left(x-x_{0}\right) \frac{\partial B_{y}}{\partial x}+\left(y-y_{0}\right) \frac{\partial B_{y}}{\partial y}+n B_{y}
\end{aligned}
$$

These equations are analogous to equation set 6 , so $n=3$ for a dipole source.

In a second approach, mentioned earlier, the Helbig method can be used to provide a continuous estimate of the total magnetization direction throughout the survey area, then this estimate can be sampled at source locations determined using a second magnetic source location method. Candidates for this second method include full Euler deconvolution as described by Reid and others (1990), various modifications of Euler deconvolution using Hilbert transforms and 
multiple sources, and non-Euler approaches using special functions such as the total gradient or the local wavenumber (Phillips and others, 2007).

\section{Dipole Moments}

Once the total magnetization directions, the horizontal locations, and the depths of the sources have been established, the dipole moments of the sources can be estimated by linear leastsquares inversion. For example, if $U_{i}(x, y)$ represents the calculated field component or tensor component of the $i$-th source with unit dipole moment and $O(x, y)$ is the observed field component or tensor component produced by all $N$ sources, then the unknown dipole moments $m_{i}$ will satisfy

$$
\sum_{i=1}^{N} U_{i}(x, y) m_{i}=O(x, y)+c
$$

in the least-squares sense, where $c$ is an unknown constant.

\section{Examples}

\section{Example 1 - Using (Noise-Free) Magnetic Field Components}

To test the method, we used the three dipole sources described in table 1 . The calculated field component grids are shown in figure $3 A$. The grids have a sample interval of $0.05 \mathrm{~m}$.

The Helbig method was applied to the field components using the following approach. The Helbig integrals of equation set 1 were evaluated in small windows centered on each grid node and having odd dimensions increasing from $3 \times 3$ to $25 \times 25$. For field components, a planar surface was removed from the component data within each window before the integration. The algorithm looked for successive solutions with increasing window size for which the total magnetization direction varied by less than a specified threshold of one degree in this case. For the grid nodes corresponding to the three dipole sources, at least 11 successive solutions with variations of less than one degree were found. For all other grid nodes, the number of successive solutions with variations of less than one degree was far fewer, between zero and six. To estimate the total magnetization direction, the successive solutions with variations of less than the threshold were averaged. The results, for averages with more than six solutions, are shown in table 2.

The simplified Euler equation (7) was used to estimate the depths of the sources. The equation was evaluated in windows of odd sizes from $3 \times 3$ to $13 \times 13$ centered on the sources. The shallowest solution for each source was selected. A magnetic potential calculated from the true sources was used. Results are shown in the "Depth" column of table 2.

The dipole moments were estimated from the three field components using a least-squares inversion and are shown in the "Moment" column of table 2. The calculated components from the estimated sources in table 2 are shown in figure $3 B$.

\section{Example 2 - Using (Noise-Free) Tensor Magnetic Gradient Components}

The three dipole sources of table 1 were used to calculate the tensor magnetic gradient components shown in figure $4 A$. The Helbig integrals in equation set 4 were evaluated in small windows centered on each grid node and having odd dimensions increasing from $3 \times 3$ to $25 \times 25$. For tensor gradient components, a mean value was removed from the gradient component data within each window before the integration. Again the algorithm looked for successive solutions with increasing window size for which the total magnetization direction varied by less than a specified 
threshold of one degree. The only solutions found were at the grid nodes corresponding to the three dipole sources. At these nodes, between 8 and 10 successive solutions with variations of less than one degree were found. To estimate the total magnetization direction, the successive solutions with variations of less than the threshold were averaged. The results are shown in table 3.

The Euler equations in set 8 were used to estimate the depths of the sources. The equations were evaluated in windows of odd sizes from $3 \times 3$ to $13 \times 13$ centered on the sources. The shallowest solution for each source was selected. Magnetic field components calculated from the true sources were used. Results are shown in the "Depth" column of table 3.

The dipole moments were estimated from the five independent gradient tensor components using a least-squares inversion and are shown in the "Moment" column of table 3 . The calculated gradient tensor components from the estimated sources in table 3 are shown in figure $4 B$.

Table 1. Dipole source parameters used to test the method.

\begin{tabular}{clccccc}
\hline Source & Easting & Northing & Depth & Inclination & Declination & Moment \\
\hline 1 & 1.0 & 1.0 & 0.20 & 0 & 30 & 0.020 \\
2 & 2.0 & 1.0 & 0.25 & 60 & -30 & 0.025 \\
3 & 1.5 & 2.0 & 0.30 & 90 & 0 & 0.030 \\
\hline
\end{tabular}

Table 2. Results of inversion using the magnetic field components.

[The eastings, northings, inclinations, and declinations are from Helbig analysis. The depths are from Euler analysis. The dipole moments are from least-squares inversion]

\begin{tabular}{lcccrrr}
\hline $\mathbf{2}$ & Easting & Northing & Depth & Inclination & Declination & Moment \\
\hline 1 & 1.0 & 1.0 & 0.191 & 0.427 & 30.063 & 0.0182 \\
2 & 2.0 & 1.0 & 0.247 & 60.149 & -29.881 & 0.0294 \\
3 & 1.5 & 2.0 & 0.300 & 89.454 & 4.108 & 0.0400 \\
\hline
\end{tabular}

Table 3. Results of inversion using the tensor magnetic gradient component.

[The eastings, northings, inclinations, and declinations are from Helbig analysis. The depths are from Euler analysis.

The dipole moments are from least-squares inversion.]

\begin{tabular}{ccccccc}
\hline Source & Easting & Northing & Depth & Inclination & Declination & Moment \\
\hline 1 & 1.0 & 1.0 & 0.200 & 0.071 & 30.055 & 0.0201 \\
2 & 2.0 & 1.0 & 0.250 & 60.154 & -30.056 & 0.0300 \\
3 & 1.5 & 2.0 & 0.300 & 89.738 & -1.541 & 0.0400 \\
\hline
\end{tabular}



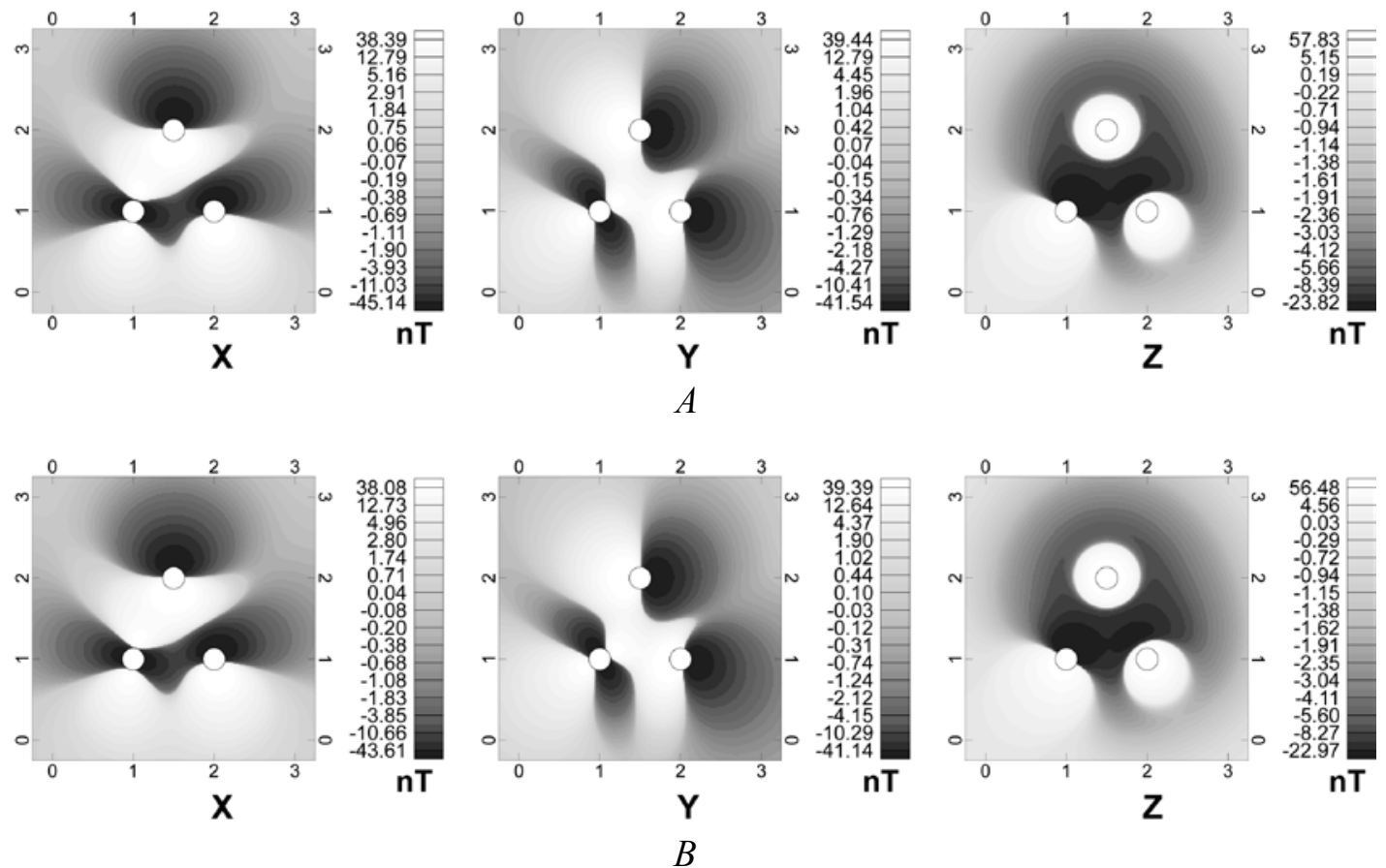

Figure 3. (A) $\mathrm{X}$ (north), $\mathrm{Y}$ (east), and $\mathrm{Z}$ (vertical) magnetic field components produced by the three test dipoles of table 1. Circles indicate the dipole locations. (B) Magnetic field components produced by the solution dipoles of table 2 . 

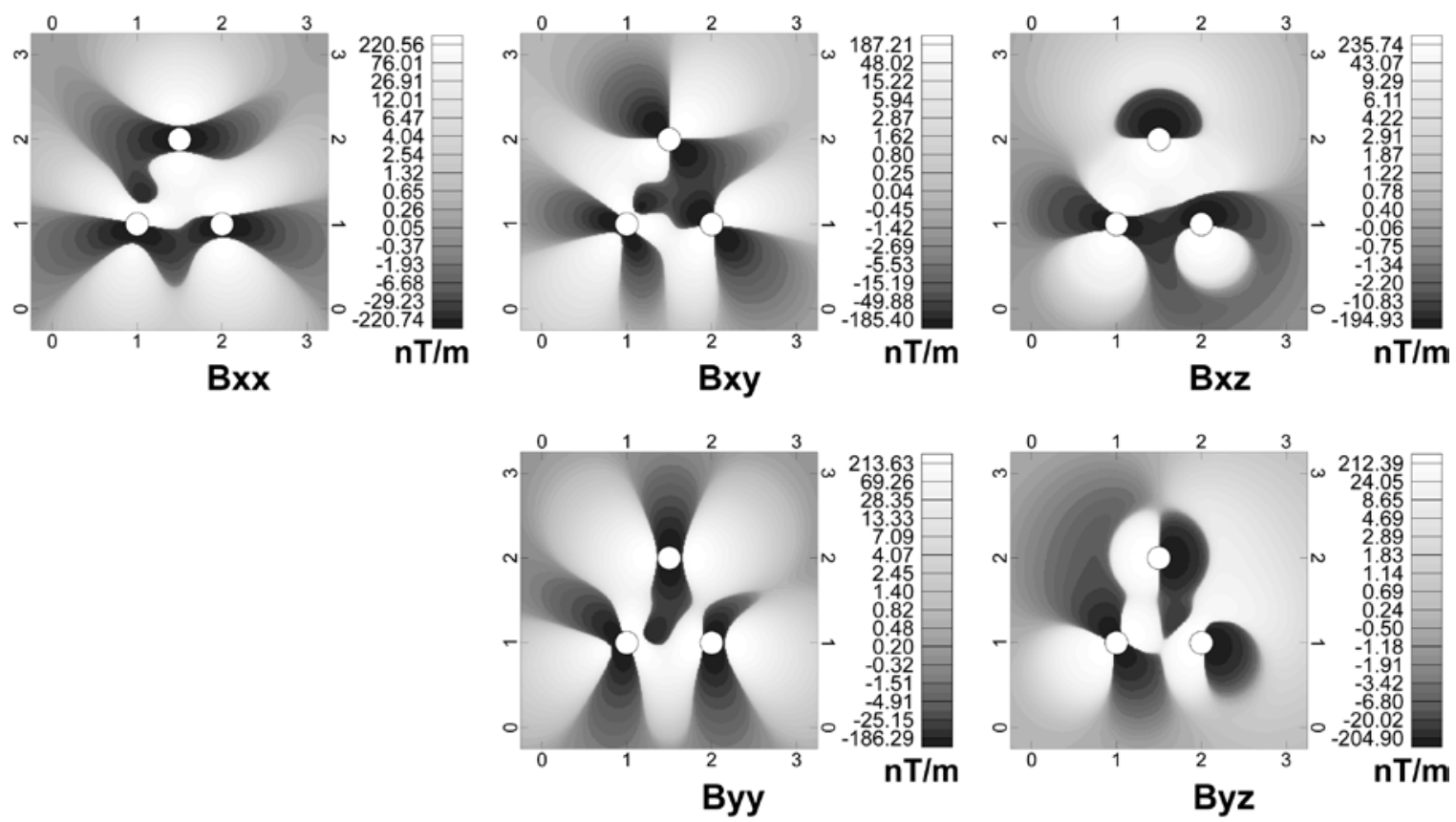

A
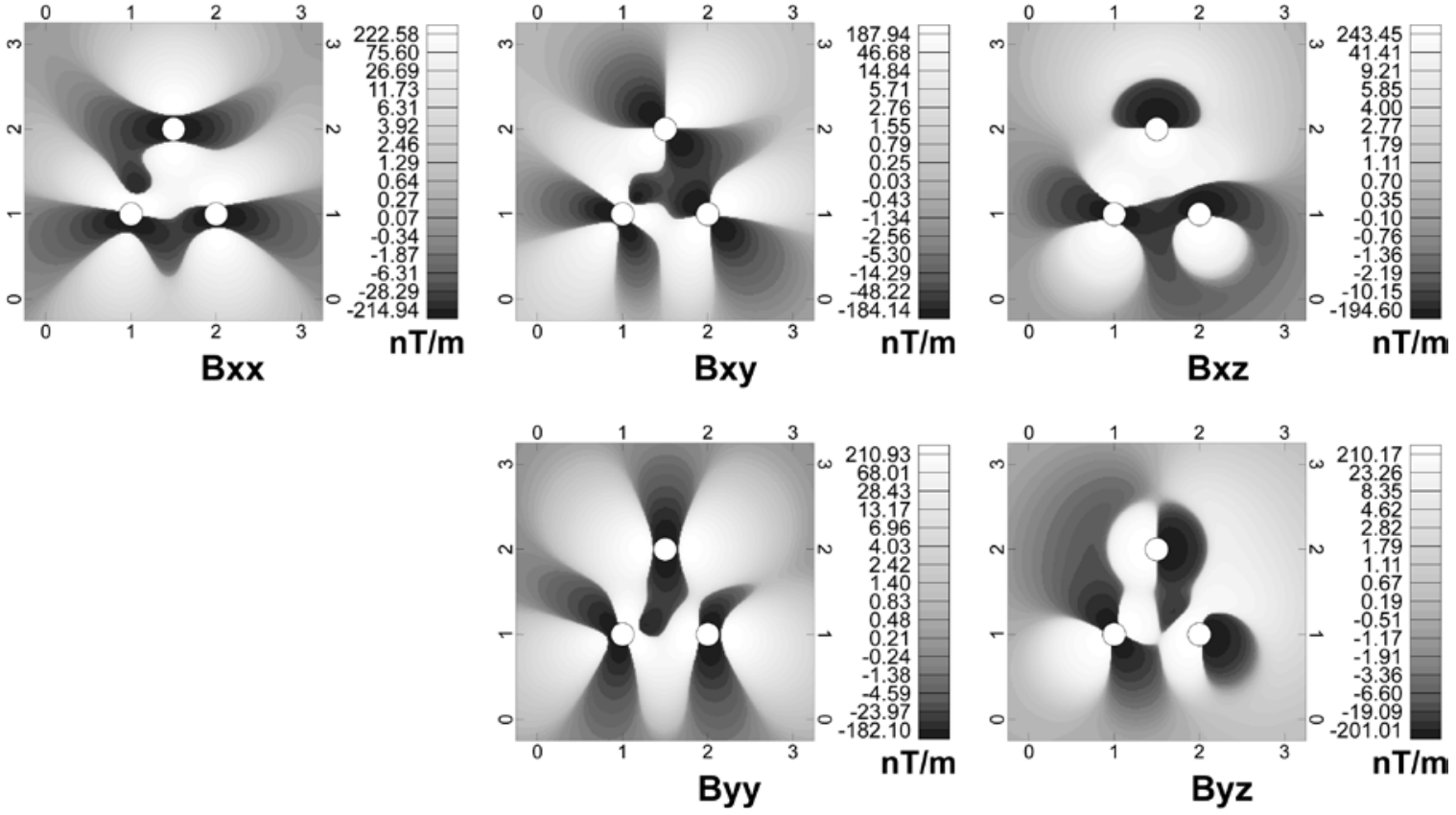

$B$

Figure 4. (A) Five independent components of the magnetic gradient tensor for the three test dipoles of table 1. Circles indicate the dipole locations. (B) Magnetic gradient tensor components produced by the solution dipoles of table 3. 


\section{Supplemental Summary of Helbig's Non-Vanishing Integrals}

Let the bivariate moments of function $f(x, y)$ be expressed as

$$
b_{i j} f=\int_{-\infty}^{\infty} \int_{-\infty}^{\infty} x^{i} y^{j} f(x, y) d x d y
$$

and let derivatives of the magnetic field components be expressed as

$$
\frac{\partial B_{z}}{\partial x}=B_{z x}, \frac{\partial^{2} B_{z}}{\partial x^{2}}=B_{z x x}
$$

Then the components of the total magnetization for a compact source can be expressed in terms of the bivariate moments of the field components, the first horizontal derivatives of the field components, and the second horizontal derivatives of the field components as

$$
\begin{aligned}
m_{x} & =-\frac{1}{2 \pi} b_{10} B_{z} \\
& =\frac{1}{4 \pi} b_{20} B_{z x}=\frac{1}{2 \pi} b_{11} B_{z y} \\
& =-\frac{1}{12 \pi} b_{30} B_{z x x}=-\frac{1}{4 \pi} b_{21} B_{z x y}=-\frac{1}{4 \pi} b_{12} B_{z y y} \\
m_{y} & =-\frac{1}{2 \pi} b_{01} B_{z} \\
& =\frac{1}{4 \pi} b_{02} B_{z y}=\frac{1}{2 \pi} b_{11} B_{z x} \\
& =-\frac{1}{12 \pi} b_{03} B_{z y y}=-\frac{1}{4 \pi} b_{12} B_{z x y}=-\frac{1}{4 \pi} b_{21} B_{z x x} \\
m_{z} & =-\frac{1}{2 \pi} b_{10} B_{x}=-\frac{1}{2 \pi} b_{01} B_{y} \\
& =\frac{1}{4 \pi} b_{20} B_{x x}=\frac{1}{4 \pi} b_{02} B_{y y}=\frac{1}{2 \pi} b_{11} B_{x y}=\frac{1}{2 \pi} b_{11} B_{y x} \\
& =-\frac{1}{12 \pi} b_{30} B_{x x x}=-\frac{1}{12 \pi} b_{03} B_{y y y}=-\frac{1}{4 \pi} b_{21} B_{x x y}=-\frac{1}{4 \pi} b_{12} B_{y x y}=-\frac{1}{4 \pi} b_{21} B_{y x x}=-\frac{1}{4 \pi} b_{12} B_{x y y}
\end{aligned}
$$

To estimate $m_{x}, m_{y}, m_{z}$ using small data windows, it is best to use square windows. To approximately satisfy Helbig's vanishing integrals, planar surfaces are removed from the field components $B_{x}, B_{y}, B_{z}$ within the window; mean values are removed from the first horizontal derivatives of the field components $B_{x x}, B_{x y}, B_{y x}, B_{y y}, B_{z x}, B_{z y}$ within the window; and nothing needs to be removed from the second horizontal derivatives within the window. Even with these corrections, numerical experiments show that the various estimates for each magnetization component are not equivalent when finite windows are used.

There is one set of total magnetization components that can be estimated from the field components: 


$$
m_{x}=-\frac{1}{2 \pi} b_{10} B_{z} \quad m_{y}=-\frac{1}{2 \pi} b_{01} B_{z} \quad m_{z}=-\frac{1}{2 \pi} b_{10} B_{x}=-\frac{1}{2 \pi} b_{01} B_{y}
$$

There are two sets that can be estimated from the first horizontal derivatives of the field components:

$$
\begin{array}{lll}
m_{x 1}=\frac{1}{4 \pi} b_{20} B_{z x} & m_{y 1}=\frac{1}{4 \pi} b_{02} B_{z y} & m_{z 1}=\frac{1}{4 \pi} b_{20} B_{x x}=\frac{1}{4 \pi} b_{02} B_{y y} \\
m_{x 2}=\frac{1}{2 \pi} b_{11} B_{z y} & m_{y 2}=\frac{1}{2 \pi} b_{11} B_{z x} & m_{z 2}=\frac{1}{2 \pi} b_{11} B_{x y}=\frac{1}{2 \pi} b_{11} B_{y x}
\end{array}
$$

In a given window, these two magnetization vectors will have equivalent directions but different magnitudes. There are three sets that can be estimated from the second horizontal derivatives of the components:

$$
\begin{array}{lll}
m_{x 1}=-\frac{1}{12 \pi} b_{30} B_{z x x} & m_{y 1}=-\frac{1}{12 \pi} b_{03} B_{z y y} & m_{z 1}=-\frac{1}{12 \pi} b_{30} B_{x x x}=-\frac{1}{12 \pi} b_{03} B_{y y y} \\
m_{x 2}=-\frac{1}{4 \pi} b_{21} B_{z x y} & m_{y 2}=-\frac{1}{4 \pi} b_{12} B_{z x y} & m_{z 2}=-\frac{1}{4 \pi} b_{21} B_{x x y}=-\frac{1}{4 \pi} b_{12} B_{y x y} \\
m_{x 3}=-\frac{1}{4 \pi} b_{12} B_{z y y} & m_{y 3}=-\frac{1}{4 \pi} b_{21} B_{z x x} & m_{z 3}=-\frac{1}{4 \pi} b_{21} B_{y x x}=-\frac{1}{4 \pi} b_{12} B_{x y y}
\end{array}
$$

These three magnetization vectors will have equivalent directions but different magnitudes in any given window.

It follows that in order to estimate total magnetization direction from the field components, $B_{z}$ and either $B_{x}$ or $B_{y}$ are necessary. In order to estimate total magnetization direction from the first horizontal derivatives of the field components, both $B_{z x}$ and $B_{z y}$ are needed and one of $B_{x x}, B_{y y}, B_{x y}$, or $B_{y x}$. In order to estimate total magnetization direction from the second horizontal derivatives of the field components, both $B_{z x x}$ and $B_{z y y}$ are needed and one of $B_{x x x}, B_{y y y}, B_{y x x}$, or $B_{x y y}$, or $B_{z x y}\left(B_{z y x}\right)$ are needed and either $B_{x x y}\left(B_{x y x}\right)$ or $B_{y x y}\left(B_{y y x}\right)$.

\section{Develop Active-Mode Algorithm}

The primary field generator is synchronized with the data acquisition system so that secondary fields are measured at primary field maxima and minima, when $\mathrm{dB} / \mathrm{dt}$ is zero. A target's location and static magnetic moment (remanent moment) are first estimated using Euler and Helbig methods. Knowing the primary coil current and radial vector to a target, one can calculate the induction field at the target's location. The induction field causes the target's total moment to rotate, which is simultaneously measured by the TMGS array. The demodulated active signal can locate ferrous targets with small or negligible remanent magnetization, as shown in figure 5. 


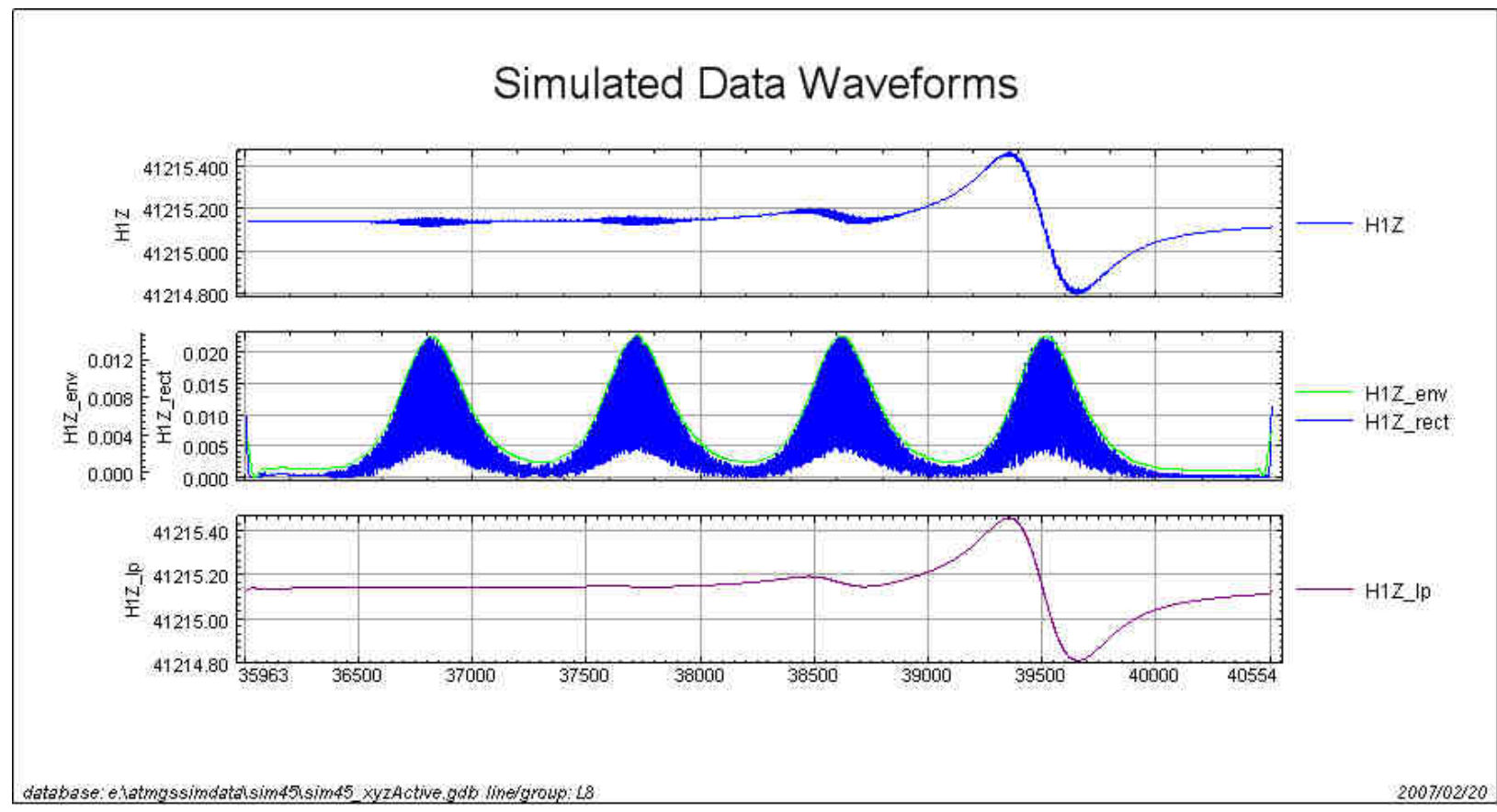

Figure 5. Simulated data waveforms for four $20-\mathrm{mm}$ spheres buried $0.02 \mathrm{~m}$ deep along a single line. The four spheres have the same magnetic permeability but different remanent magnetization (increasing from left to right). The top plot shows the $z$-component of head 1. Separation of the active signal (blue) from the static signal (purple) is achieved by simple high-pass and low-pass filtering, respectively. The inductive response for the four spheres is identical, but the static magnetic anomaly (bottom plot) from each differs according to their magnetic moments.

Figure 6 shows plots of the ATMGS received signal (red) and the static (green) and active (blue) waveforms for the head $1 z$-component along a line over three targets in the standard model.

The bottom panel plots the rectified active signal (magenta) and its demodulation or envelope (gray). The primary field oscillation can be seen in the close-up in figure 7. The low-pass signal is the static magnetic field over the targets. A vector sum of the three orthogonal magnetic components of a single magnetometer head produces a total field map, as shown in figure 8 . The total field data can be processed and gridded using standard potential field algorithms, such as those contained in the magmap.omn and ux-detect.omn utility menus in Oasis montaj. By contrast, the envelope provides a means of mapping isolated ferrous targets with sharp definition, as illustrated in figure 9 . 


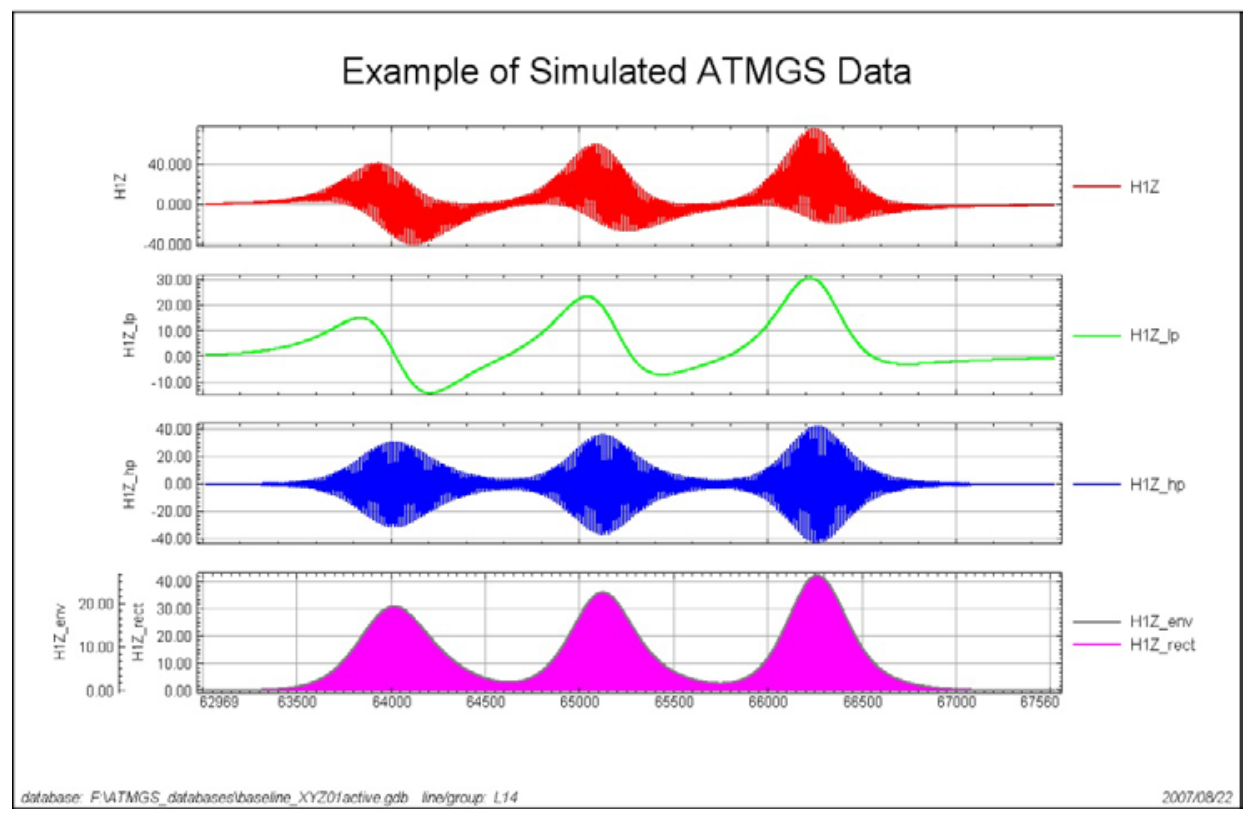

Figure 6. Example of simulated data along line over three 60-mm targets in the standard model. Shown are the received signal from head $1 z$-component (red), the static signal (green), the active signal (blue) and the rectified (magenta) and demodulated signal (gray).

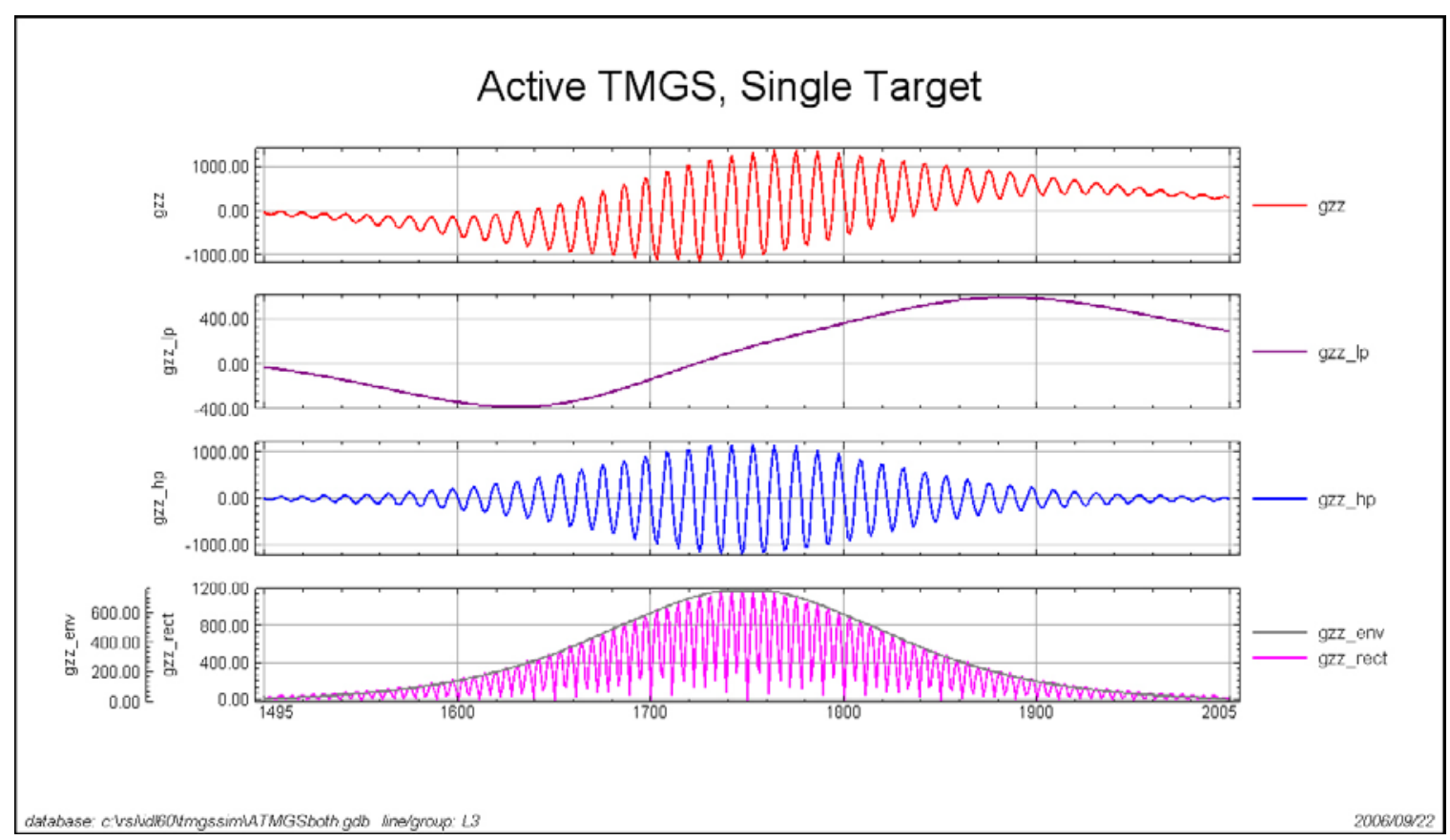

Figure 7. Active tensor magnetic gradiometer system output. Close up of simulation data over a single 60$\mathrm{mm}$ target in the standard model. Shown are the received signal from head $1 \mathrm{z}$-component (red), the static signal (purple), the active signal (blue) and the rectified (magenta) and demodulated signal (gray). 


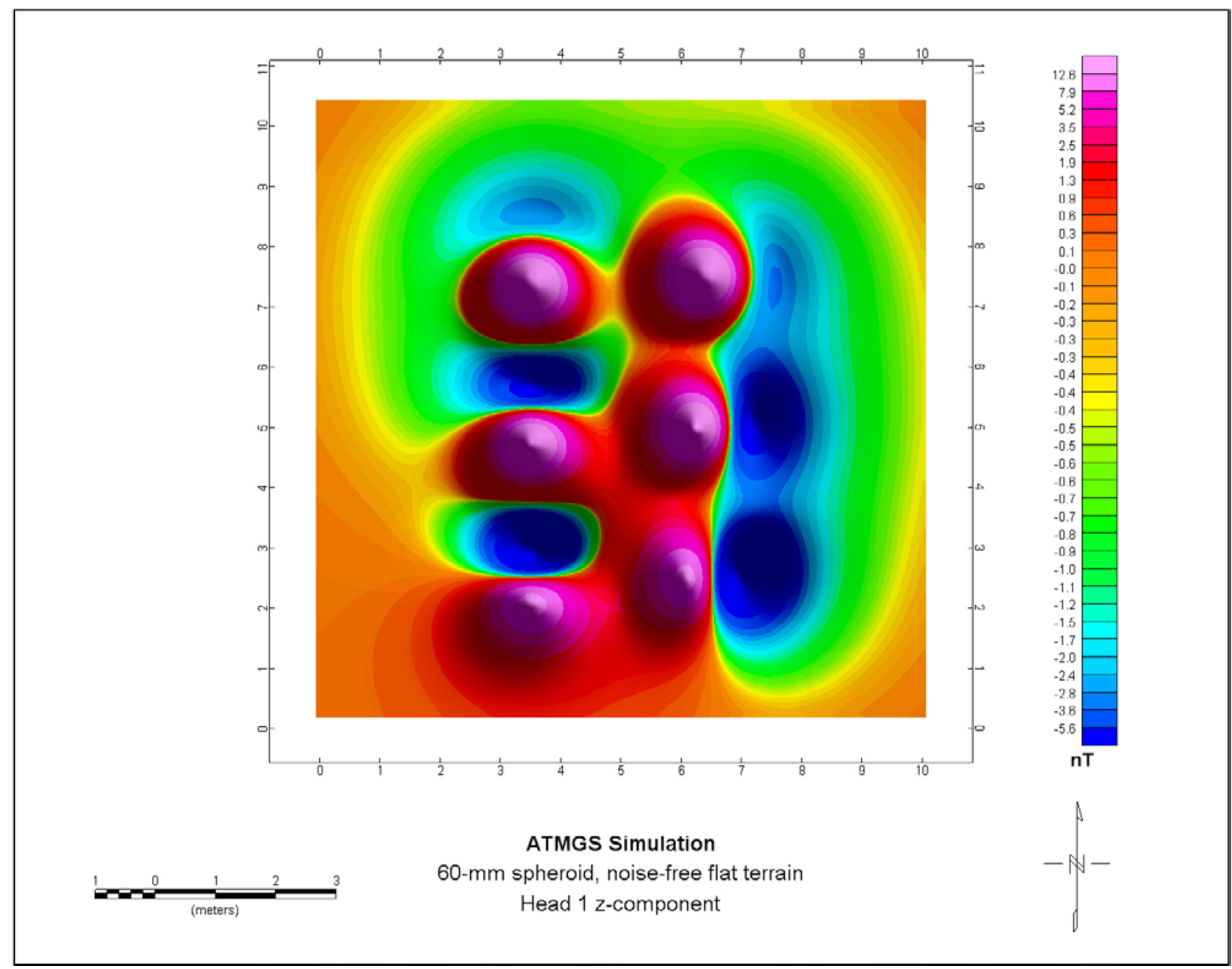

Figure 8. Map of head1 z-component only of static anomalies of six $60-\mathrm{mm}$ targets in the standard model. 


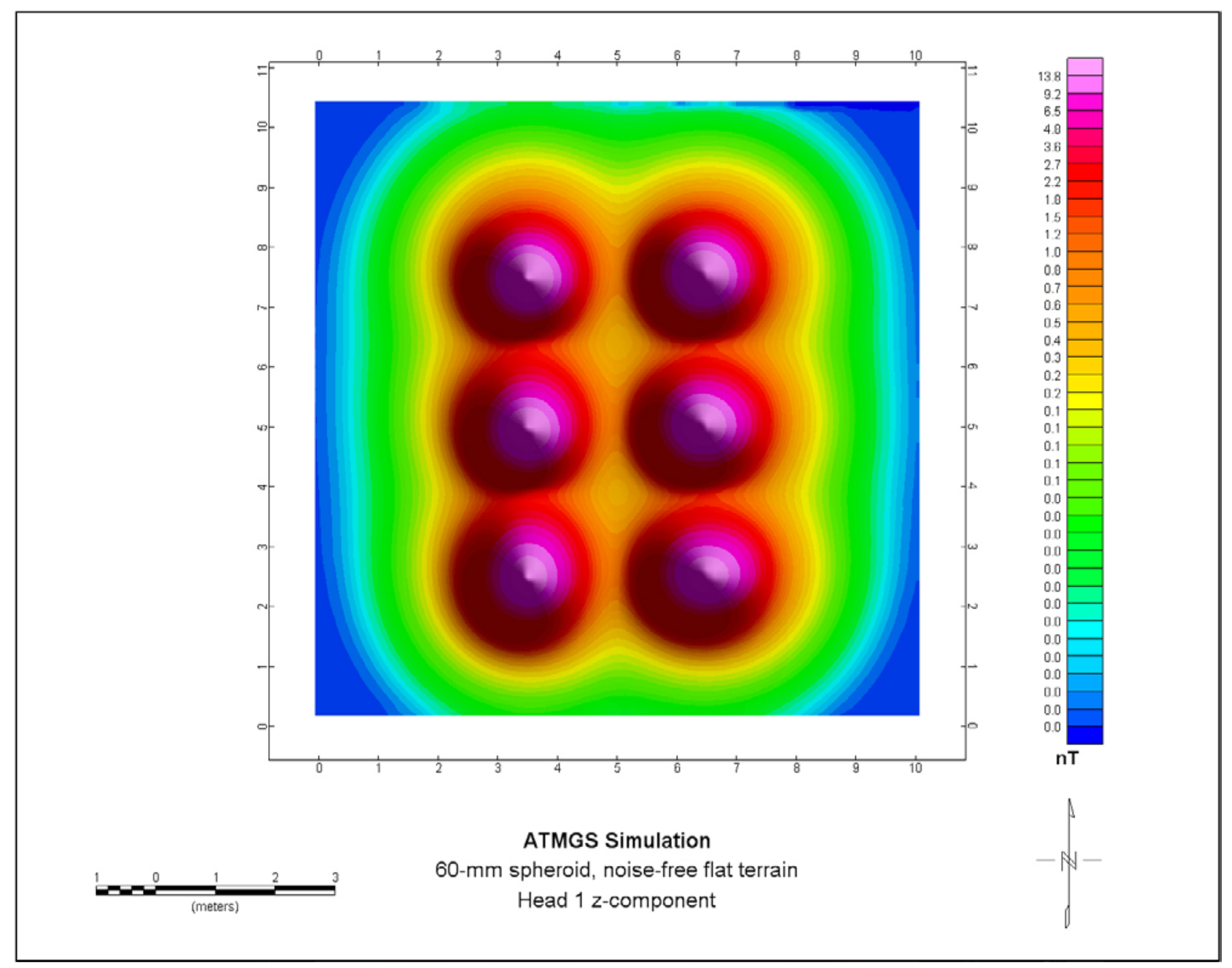

Figure 9. Demodulated (envelope) active component of six isolated 60-mm targets in the standard model.

This research project investigated what information can be gleaned from the active signals and the active signal gradients $\mathrm{G}_{\mathrm{ij}}$ calculated by differencing opposite pairs of magnetometer axes and dividing by their baseline separation. A following section "Develop Induced/Remanence Algorithms) describes analysis of active tensor data in an attempt to separate the remanent and induced magnetization of a ferrous body. This section describes research into determining the spheroidal geometry of a target from active magnetic gradient data, and thereby discriminating UXO-like targets from scrap-like targets.

\section{Develop Discrimination Algorithms}

The problem of discrimination using magnetics has focused mainly on estimating the remanent magnetic moment of a target by looking at the magnitude and direction of its dipole moment and plotting those values against what would be expected of a purely induced moment in a degaussed target in the Earth's ambient field (Billings, 2002). The assumed degaussing occurs as shock demagnetization when the ordnance item strikes the ground. This method has been shown to improve discrimination of intact UXO and clutter by 50 percent. 
We take a different approach that uses all the information provided by the ATMGS. Because six discrete magnetic gradients $G_{i j}$ are measured simultaneously at 900 readings per second, it is possible to pick the $G_{i j}$ that occur at minima and maxima of the primary drive field over a target. At these instants, the primary field is at maximum magnitude and $d B / d t$ is zero. Therefore, purely magnetostatic equations apply to the magnetic induction of a spheroidal body. As noted before, intact UXO can be adequately approximated by a spheroid, and a hollow spheroid can be adequately approximated by a solid spheroid. A simple thresholding technique on the magnetic $z$-components can isolate the $G_{i j}$ used to invert for the instantaneous magnetic moment. The result of this selection over a single target is shown in figure 10, in which different colors correspond to the $z$-component of different magnetometer heads.

At each of the measurement locations, the six $G_{i j}$ are inverted to solve for the magnetic moment $\left(M_{x}, M_{y}, M_{z}\right)$ at the target location. A comparison of the inversion solutions $\left(M_{s}\right)$ to the true induced moments $\left(M_{i}\right)$ is plotted in figure 11. This is for the ideal case of no noise and horizontal, flat terrain. The agreement, though quite close, is not exact. The addition of system noise and terrain effects causes further divergence between the ideal and the more realistic cases, as illustrated in figure 12. The worst case combines system noise and terrain effects.

Having determined the induced moment at each measurement location, we find it possible to invert to a spheroidal model using the following procedure:

- Knowing the location and attitude of the sensor array and primary coil at each measurement point, calculate the $r$-vectors to the target's location.

- Calculate the magnetic field components of the primary coil at the target's location for each $r$ vector.

- Knowing the $r$-vectors, the induced moments, and the primary coil magnetic field components, invert to a magnetically permeable spheroid at the target's location.

The result of this procedure on the worst case simulation is given in figure 13 for spheroids with a diameter $c$ of $60 \mathrm{~mm}$ but differing lengths $a$. Plate-like bodies are simulated by oblate spheroids with $a<<c$, whereas rod-like bodies are simulated by prolate spheroids with $a>c$. UXO-like bodies have an $a: c$ ratio between 2 and 4. Simulation scenarios 1-5 for maximum primary field strength (maxima in the active signal) are increasingly prolate, compared to scenarios 6-9, which are increasingly oblate. This pattern repeats for scenarios 10-18, which are solutions for minimum primary field strength (minima in the active signal). Because of symmetry, the positive and negative solutions are very nearly identical. The $60-\mathrm{mm}$ target spheroid is represented by scenario 1 and scenario 10 . Figure 14 shows the results plotted against the ratio $a: c$, where the 60 $\mathrm{mm}$ target's ratio is 2 . 


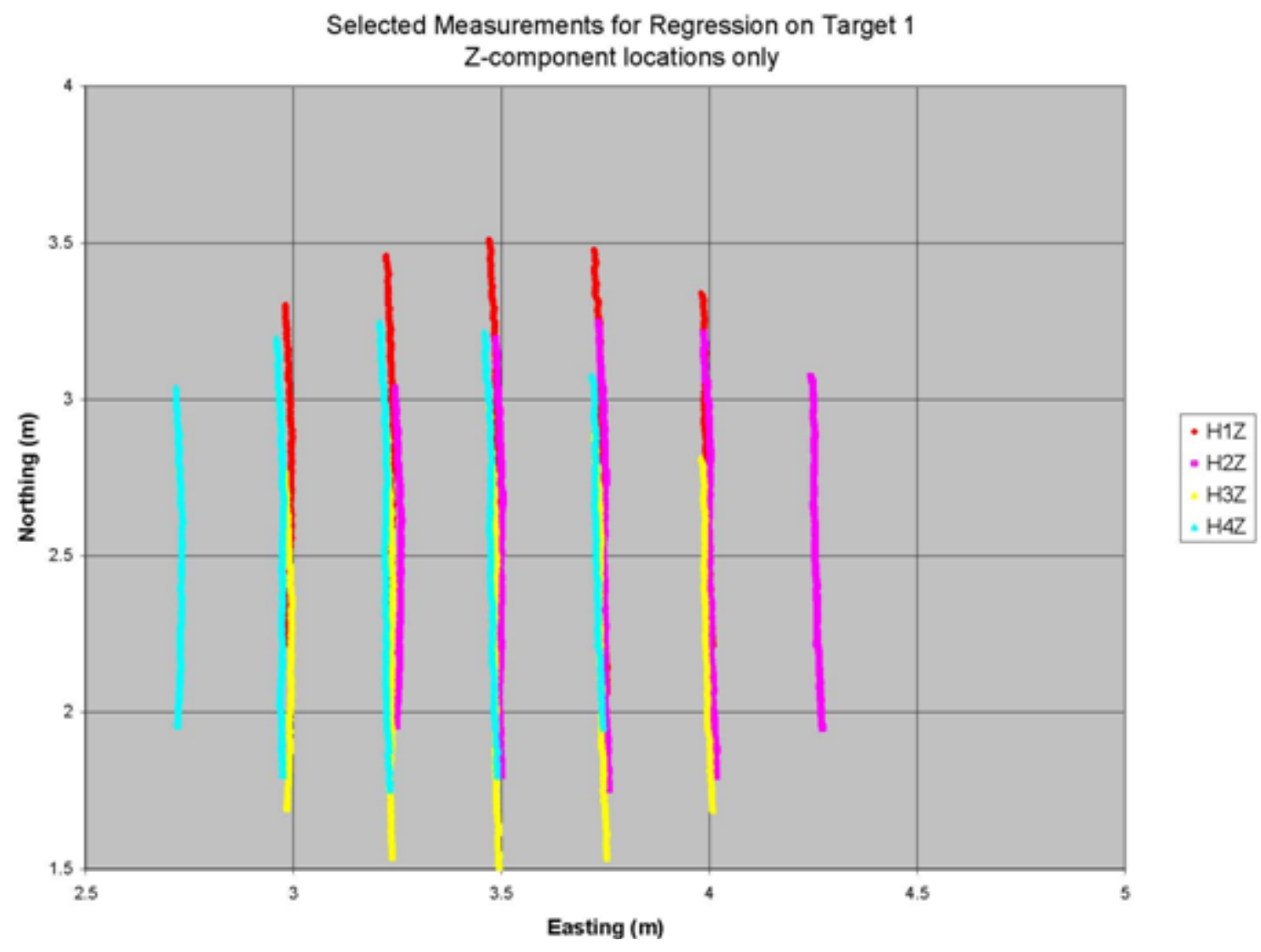

Figure 10. Map of maxima/minima of active component selected for inversion to induced moments. The locations of different magnetic z-components (red, magenta, yellow, blue) are offset because of the physical separation of the fluxgate heads on the array. The lines are irregular because of terrain effects. 


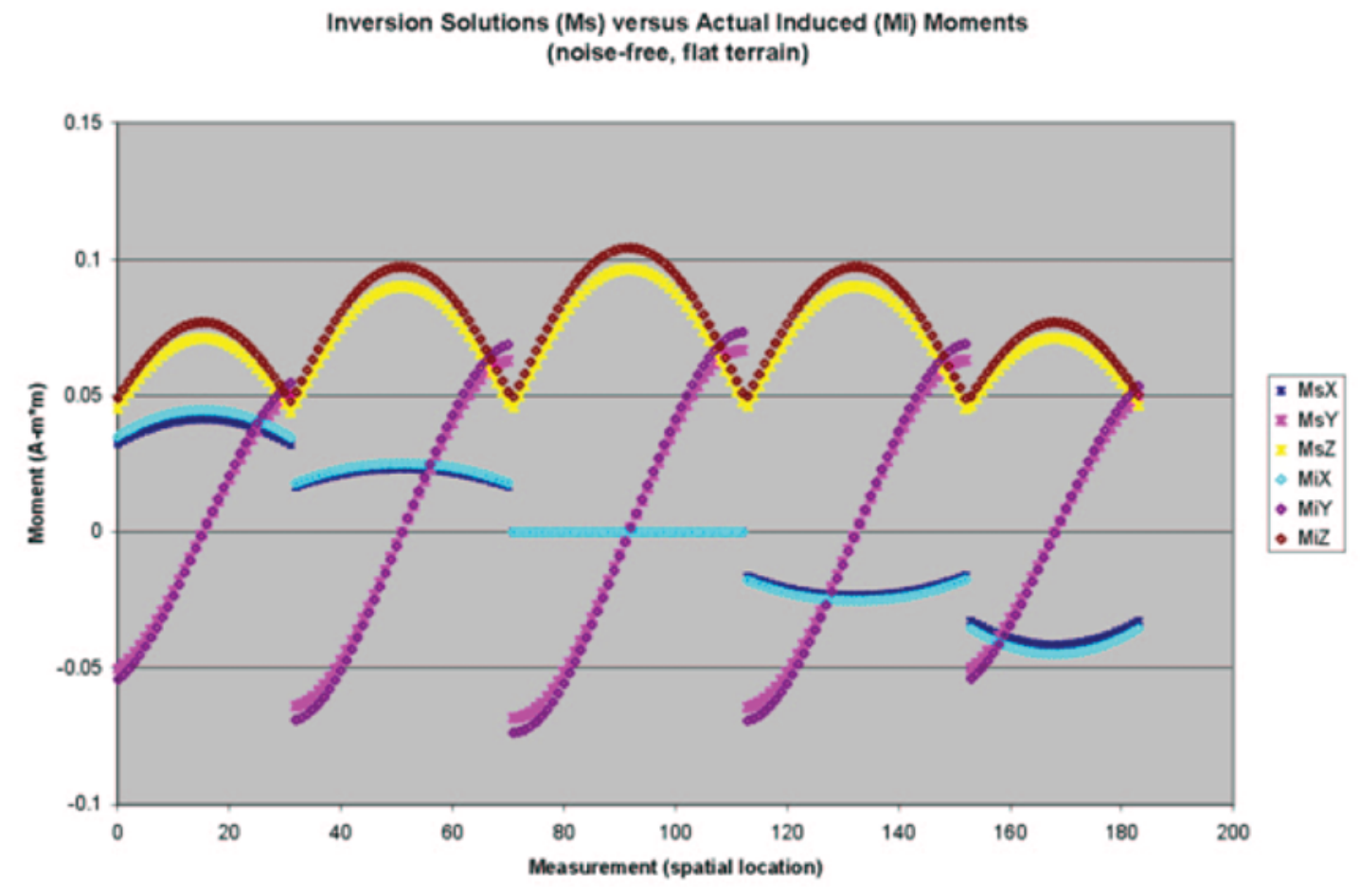

Figure 11. Recovered moments $\left(M_{s}\right)$ versus actual induced moments $\left(M_{i}\right)$. True moment values are slightly greater in magnitude than the moments recovered through inversion. 
Recovered Moments

for Four Simulation Cases

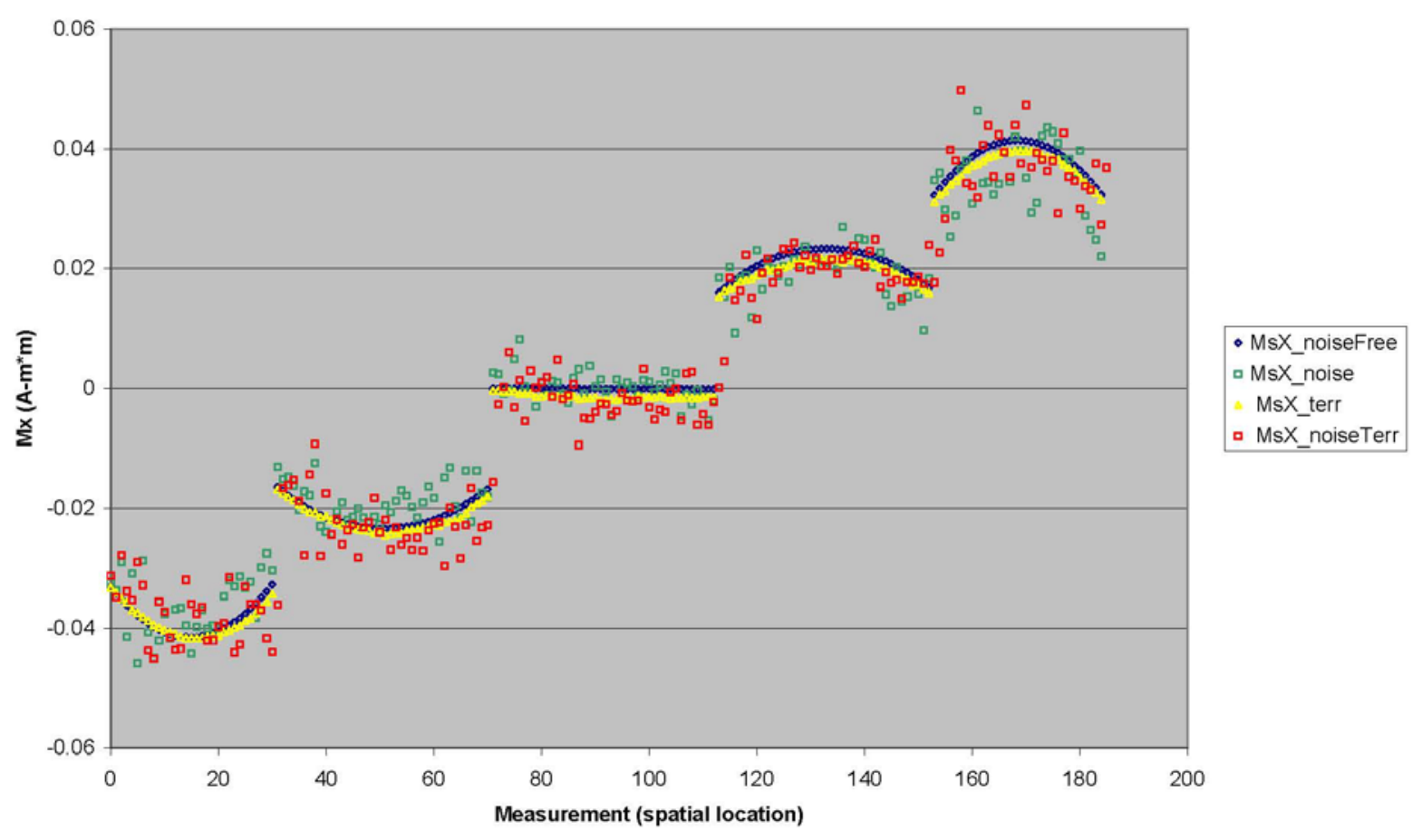

Figure 12. Effects of noise sources on recovered moments. Solid diamond is noise free; hollow blue square is with system noise; yellow triangle is with terrain effects; and red square is with both noise and terrain effects. 
Recovered Spheroid Dimensions

(system noise, uneven terrain)

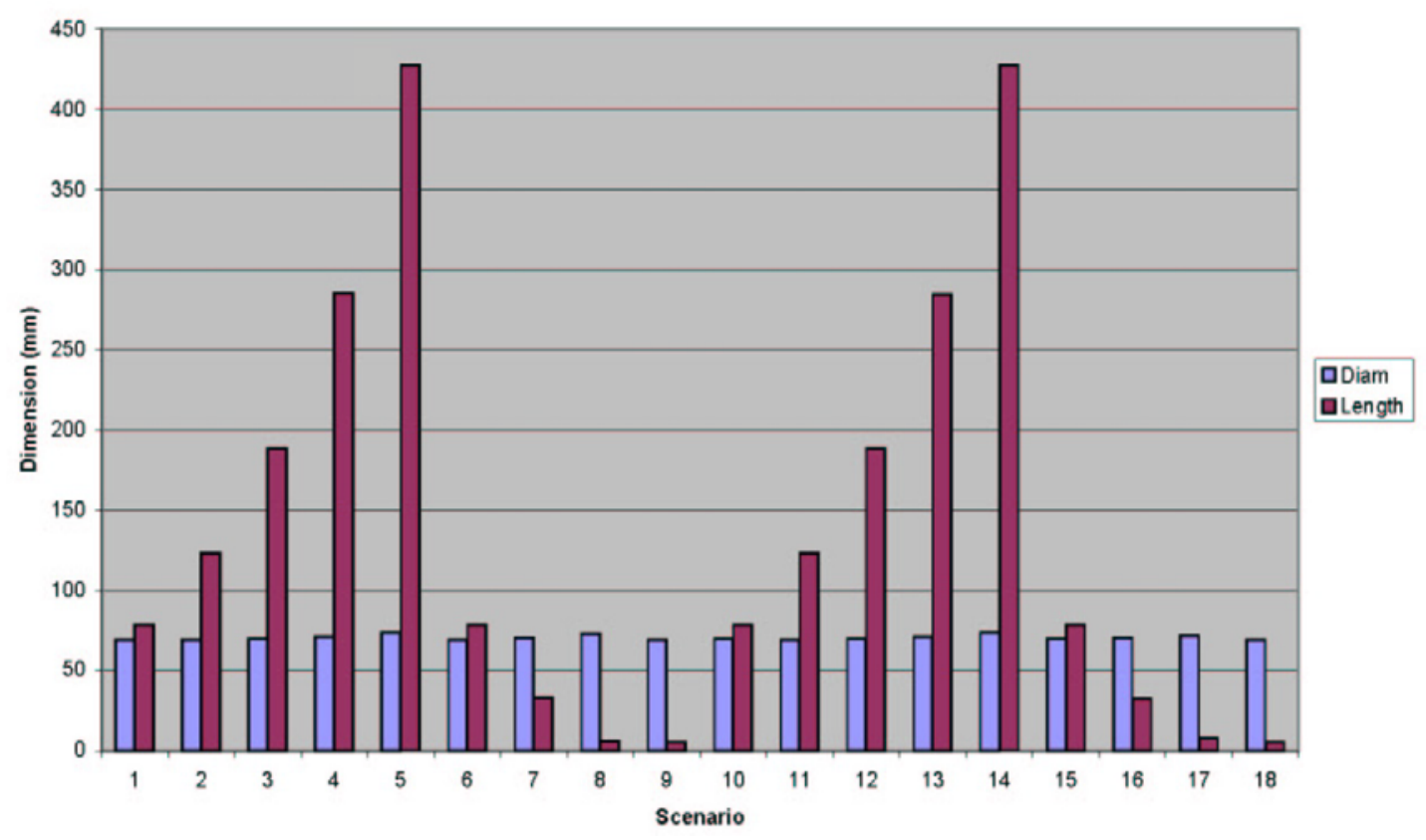

Figure 13. Recovered spheroid dimensions for modeled spheroids. Scenario 1 and scenario 10 represent the $60-\mathrm{mm}$ spheroid. Scenarios $1-5$ are increasingly prolate, whereas scenarios $6-9$ are increasingly oblate. Scenarios $1-9$ are solutions based on primary field maxima, and scenarios $10-18$ are from primary field minima. 

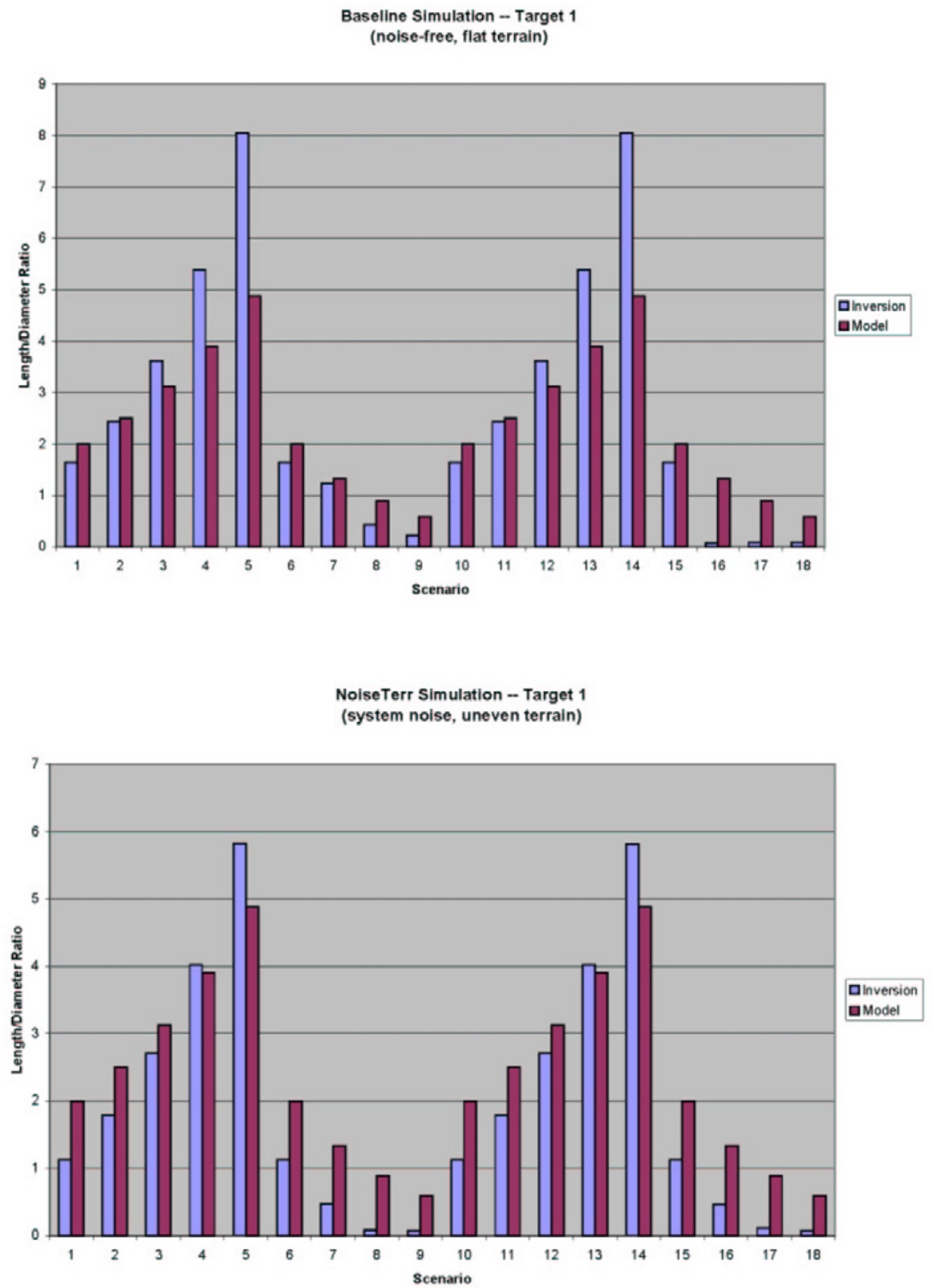

Figure 14. Histograms of length-to-diameter ratios. The ratio of length to diameter is diagnostic of whether a target is UXO-like or scrap-like. The 60-mm target has a ratio of 2.

\section{Develop Induced/Remanence Algorithms}

Two Helbig-Euler simulations were run with rectangular source bodies to test the ability of the active system to recover the moments, susceptibilities, and Koenigsberger ratios of non-dipole sources. The Koenigsberger ratio $\mathrm{Q}$ is defined as the ratio of the remanent magnetization to the induced magnetization. One simulation involved rod-like sources, the other involved plate-like sources. 
The rod simulation involved three rectangular rods 5 units long by 1 unit by 1 unit oriented along the east, north, and vertical axes; three rectangular rods 3 units long by 1 unit by 1 unit also oriented along the east, north, and vertical axes; and three 1-unit cubes. One unit equals $0.25 \mathrm{~m}$. The centers of the sources were 4 units below the sensors. The rods had remanent magnetizations oriented along their long axes, and the three cubes had remanent magnetizations in the three orthogonal directions. The remanent magnetization intensities were set so that the equivalent dipole moments of the sources were roughly the same. The model is described in table 4.

Table 4. Parameters for the rod model.

$\left[\mathrm{A}-\mathrm{m}^{2}\right.$, ampere $\mathrm{x}$ meter $\left.^{2}\right]$

\begin{tabular}{ccccccc}
\hline $\begin{array}{c}\text { Easting } \\
\text { (meters) }\end{array}$ & $\begin{array}{c}\text { Northing } \\
\text { (meters) }\end{array}$ & $\begin{array}{c}\text { Depth } \\
\text { (meters) }\end{array}$ & $\begin{array}{c}\text { Inclination } \\
\text { (degrees) }\end{array}$ & $\begin{array}{c}\text { Declination } \\
\text { (degrees) }\end{array}$ & $\begin{array}{c}\text { Moment } \\
\left(\text { A-m }{ }^{2}\right)\end{array}$ & Aspect \\
\hline 3.5 & 2.5 & 1.0 & 0.0 & 0.0 & 0.078125 & $1 \times 5 \times 1$ \\
6.5 & 2.5 & 1.0 & 0.0 & 90.0 & 0.078125 & $5 \times 1 \times 1$ \\
9.5 & 2.5 & 1.0 & 90.0 & $* 1$ & 0.078125 & $1 \times 1 \times 5$ \\
3.5 & 5.0 & 1.0 & 0.0 & 0.0 & 0.093750 & $1 \times 3 \times 1$ \\
6.5 & 5.0 & 1.0 & 0.0 & 90.0 & 0.093750 & $3 \times 1 \times 1$ \\
9.5 & 5.0 & 1.0 & 90.0 & $*$ & 0.093750 & $1 \times 1 \times 3$ \\
3.5 & 7.5 & 1.0 & 0.0 & 0.0 & 0.078125 & $1 \times 1 \times 1$ \\
6.5 & 7.5 & 1.0 & 0.0 & 90.0 & 0.078125 & $1 \times 1 \times 1$ \\
9.5 & 7.5 & 1.0 & 90.0 & $*$ & 0.078125 & $1 \times 1 \times 1$ \\
\hline
\end{tabular}

${ }^{1}$ Because the inclination is vertical, the declination can take on any value.

A Helbig-Euler inversion on the vector components without any inducing field was able to recover the locations and magnetizations of nine equivalent dipole sources (table 5). The equivalent dipole sources for the vertically oriented rods are shallow but below the tops of the rods.

Table 5. Results of Helbig-Euler inversion on the rod model without any inducing field. $\left[\mathrm{A}-\mathrm{m}^{2}\right.$, ampere $\mathrm{x}$ meter $\left.^{2}\right]$

\begin{tabular}{ccccccc}
\hline $\begin{array}{c}\text { Easting } \\
\text { (meters) }\end{array}$ & $\begin{array}{c}\text { Northing } \\
\text { (meters) }\end{array}$ & $\begin{array}{c}\text { Depth } \\
\text { (meters) }\end{array}$ & $\begin{array}{c}\text { Inclination } \\
\text { (degrees) }\end{array}$ & $\begin{array}{c}\text { Declination } \\
\text { (degrees) }\end{array}$ & $\begin{array}{c}\text { Moment } \\
\left(\mathbf{A}-\mathrm{m}^{2}\right)\end{array}$ & Aspect \\
\hline 3.5 & 2.5 & 1.0761 & -2.7667 & 0.0564 & 0.068555 & $1 \times 5 \times 1$ \\
6.5 & 2.5 & 1.4324 & 0.0766 & 90.1459 & 0.120341 & $5 \times 1 \times 1$ \\
9.5 & 2.5 & 0.5847 & 89.8303 & 22.9334 & 0.039192 & $1 \times 1 \times 5$ \\
3.5 & 5.0 & 0.9547 & -0.1952 & 0.1755 & 0.073168 & $1 \times 3 \times 1$ \\
6.5 & 5.0 & 1.1522 & 0.2337 & 90.0532 & 0.111400 & $3 \times 1 \times 1$ \\
9.5 & 5.0 & 0.8358 & 89.8144 & 56.1906 & 0.072610 & $1 \times 1 \times 3$ \\
3.5 & 7.5 & 0.9219 & 0.9035 & 0.1408 & 0.062294 & $1 \times 1 \times 1$ \\
6.5 & 7.5 & 0.9812 & 0.0367 & 90.1043 & 0.073405 & $1 \times 1 \times 1$ \\
9.5 & 7.5 & 0.9952 & 89.7147 & 146.2096 & 0.076875 & $1 \times 1 \times 1$ \\
\hline
\end{tabular}

To simulate the peak response of the active system, a vertical inducing field was applied to the model under the assumption that all sources had a Koenigsberger ratio of 1.0. Table 6 shows the results of a Helbig-Euler inversion on the vector components with the inducing field in the 
downward direction, and table 7 shows the results on the vector components with the inducing field in the upward direction. Note that the upward-inducing field exactly cancels the field of the three source bodies with vertical remanent magnetization.

Table 6. Results of Helbig-Euler inversion on the rod model with downward-inducing field. $\left[\mathrm{A}-\mathrm{m}^{2}\right.$, ampere $\mathrm{x}$ meter $\left.{ }^{2}\right]$

\begin{tabular}{ccccccc}
\hline $\begin{array}{c}\text { Easting } \\
\text { (meters) }\end{array}$ & $\begin{array}{c}\text { Northing } \\
\text { (meters) }\end{array}$ & $\begin{array}{c}\text { Depth } \\
\text { (meters) }\end{array}$ & $\begin{array}{c}\text { Inclination } \\
\text { (degrees) }\end{array}$ & $\begin{array}{c}\text { Declination } \\
\text { (degrees) }\end{array}$ & $\begin{array}{c}\text { Moment } \\
(\text { A-m })^{2}\end{array}$ & Aspect \\
\hline 3.5 & 2.5 & 0.9016 & 52.54576 & 0.152 & 0.0691042 & $1 \times 5 \times 1$ \\
6.5 & 2.5 & 1.3690 & 53.97548 & 89.669 & 0.1503845 & $5 \times 1 \times 1$ \\
9.5 & 2.5 & 0.5829 & 89.47509 & -4.957 & 0.0775733 & $1 \times 1 \times 5$ \\
3.5 & 5.0 & 0.9764 & 46.90822 & 0.974 & 0.1117457 & $1 \times 3 \times 1$ \\
6.5 & 5.0 & 1.1366 & 47.18464 & 89.275 & 0.1494823 & $3 \times 1 \times 1$ \\
9.5 & 5.0 & 0.8284 & 89.64802 & 2.382 & 0.1418990 & $1 \times 1 \times 3$ \\
3.5 & 7.5 & 1.0266 & 45.69145 & 0.225 & 0.1120025 & $1 \times 1 \times 1$ \\
6.5 & 7.5 & 0.9771 & 45.00643 & 91.085 & 0.1032609 & $1 \times 1 \times 1$ \\
9.5 & 7.5 & 0.9793 & 89.30260 & 175.421 & 0.1486813 & $1 \times 1 \times 1$ \\
\hline
\end{tabular}

Table 7. Results of Helbig-Euler inversion on the rod model with upward-inducing field.

$\left[\mathrm{A}-\mathrm{m}^{2}\right.$, ampere $\mathrm{x}$ meter $\left.^{2}\right]$

\begin{tabular}{ccccccc}
\hline $\begin{array}{c}\text { Easting } \\
\text { (meters) }\end{array}$ & $\begin{array}{c}\text { Northing } \\
\text { (meters) }\end{array}$ & $\begin{array}{c}\text { Depth } \\
\text { (meters) }\end{array}$ & $\begin{array}{c}\text { Inclination } \\
\text { (degrees) }\end{array}$ & $\begin{array}{c}\text { Declination } \\
\text { (degrees) }\end{array}$ & $\begin{array}{c}\text { Moment } \\
\left(\text { A-m }{ }^{2}\right)\end{array}$ & Aspect \\
\hline 3.5 & 2.5 & 1.2782 & -54.5383 & -0.1704 & 0.1427875 & $1 \times 5 \times 1$ \\
6.5 & 2.5 & 1.3805 & -53.9433 & 90.5759 & 0.1689254 & $5 \times 1 \times 1$ \\
9.5 & 2.5 & $* 1$ & $*$ & $*$ & $*$ & $1 \times 1 \times 5$ \\
3.5 & 5.0 & 0.9629 & -47.0065 & 0.0201 & 0.1133776 & $1 \times 3 \times 1$ \\
6.5 & 5.0 & 1.1371 & -46.3786 & 89.8697 & 0.1578909 & $3 \times 1 \times 1$ \\
9.5 & 5.0 & $*$ & $*$ & $*$ & $*$ & $1 \times 1 \times 3$ \\
3.5 & 7.5 & 0.8343 & -43.7581 & 0.0357 & 0.0754909 & $1 \times 1 \times 1$ \\
6.5 & 7.5 & 0.9796 & -44.9590 & 89.1212 & 0.1040951 & $1 \times 1 \times 1$ \\
9.5 & 7.5 & $*$ & $*$ & $*$ & $*$ & $1 \times 1 \times 1$ \\
\hline
\end{tabular}

${ }^{1}$ No values because the inducing field exactly cancels the remanent field.

The total magnetization vector for each source changes direction and magnitude as a result of the vertical inducing field. The magnetic susceptibility of each source is given by the magnitude of the change in the vertical component of magnetization divided by the inducing field strength. The Koenigsberger ratio Q of each source is the ratio of the remanent magnetization to the induced magnetization. This is equivalent to the ratio of the dipole moment without an inducing field to the product of the magnetic susceptibility and the inducing field strength, or to the ratio of the dipole moment without an inducing field to the magnitude of the change in the vertical component of magnetization. Table 8 shows the estimated magnetic susceptibility and Koenigsberger ratio for each source. 
Table 8. Estimated magnetic susceptibilities and Koenigsberger ratios for the rod model. [Q, Koenigsberger ratio; Susc., magnetic susceptibility]

\begin{tabular}{cccccccc}
\hline \multirow{2}{*}{$\begin{array}{c}\text { Easting } \\
\text { (meters) }\end{array}$} & \multirow{2}{*}{$\begin{array}{c}\text { Northing } \\
\text { (meters) }\end{array}$} & \multicolumn{2}{c}{ Downward field } & \multicolumn{2}{c}{ Upward field } & \multicolumn{2}{c}{ Average } \\
\cline { 3 - 7 } & Susc. & $\mathbf{Q}$ & Susc. & $\mathbf{Q}$ & Susc. & $\mathbf{Q}$ \\
\hline 3.5 & 2.5 & 0.058167 & 1.178594 & 0.112992 & 0.606725 & 0.085579 & 0.892660 \\
6.5 & 2.5 & 0.121465 & 0.990744 & 0.136726 & 0.880158 & 0.129096 & 0.935451 \\
9.5 & 2.5 & 0.038378 & 1.021210 & 0.038378 & 1.021210 & 0.038378 & 1.021210 \\
3.5 & 5.0 & 0.081853 & 0.893898 & 0.082679 & 0.884969 & 0.082266 & 0.889433 \\
6.5 & 5.0 & 0.109198 & 1.020164 & 0.114754 & 0.970772 & 0.111976 & 0.995468 \\
9.5 & 5.0 & 0.069287 & 1.047956 & 0.069287 & 1.047956 & 0.069287 & 1.047956 \\
3.5 & 7.5 & 0.079165 & 0.786883 & 0.053193 & 1.171093 & 0.066179 & 0.978988 \\
6.5 & 7.5 & 0.072978 & 1.005850 & 0.073601 & 0.997336 & 0.073289 & 1.001593 \\
9.5 & 7.5 & 0.071796 & 1.070750 & 0.071796 & 0.070750 & 0.071796 & 1.070750 \\
\hline
\end{tabular}

Note that the estimated susceptibilities are close to the true susceptibilities of 0.78 to 0.94 , and the estimated Q-values are all close to the true value of 1.0. There is no apparent way to distinguish between the small cube-like bodies that approximate true dipoles and the rod-like sources.

The plate simulation involved three large rectangular plates of dimensions 5 units $\mathrm{x} 5$ units $\mathrm{x} 1$ unit oriented with the normal to the large surface directed along the east, north, and vertical axes; three smaller rectangular plates 3 units x 3 units $\times 1$ unit also oriented along the east, north, and vertical axes; and three 1-unit cubes. One unit equals $0.25 \mathrm{~m}$. The centers of the sources were 4 units below the sensors. The plates had remanent magnetizations oriented along the normal to their larger surfaces, and the three cubes had remanent magnetizations in the three orthogonal directions. The remanent magnetization intensities were set so that the equivalent dipole moments of the sources were roughly the same. The model is described in table 9.

Table 9. Parameters for the plate model.

$\left[\mathrm{A}-\mathrm{m}^{2}\right.$, ampere $\mathrm{x}$ meter $\left.^{2}\right]$

\begin{tabular}{ccccccc}
\hline $\begin{array}{c}\text { Easting } \\
\text { (meters) }\end{array}$ & $\begin{array}{c}\text { Northing } \\
\text { (meters) }\end{array}$ & $\begin{array}{c}\text { Depth } \\
\text { (meters) }\end{array}$ & $\begin{array}{c}\text { Inclination } \\
\text { (degrees) }\end{array}$ & $\begin{array}{c}\text { Declination } \\
\text { (degrees) }\end{array}$ & $\begin{array}{c}\text { Moment } \\
\left(\mathbf{A}-\mathbf{m}^{2}\right)\end{array}$ & Aspect \\
\hline 3.5 & 2.5 & 1.0 & 0 & 90 & 0.390625 & $1 \times 5 \times 5$ \\
6.5 & 2.5 & 1.0 & 0 & 0 & 0.390625 & $5 \times 1 \times 5$ \\
9.5 & 2.5 & 1.0 & 90 & $* 1$ & 0.390625 & $5 \times 5 \times 1$ \\
3.5 & 5.0 & 1.0 & 0 & 90 & 0.421875 & $1 \times 3 \times 3$ \\
6.5 & 5.0 & 1.0 & 0 & 0 & 0.421875 & $3 \times 1 \times 3$ \\
9.5 & 5.0 & 1.0 & 90 & $*$ & 0.421875 & $3 \times 3 \times 1$ \\
3.5 & 7.5 & 1.0 & 0 & 90 & 0.390625 & $1 \times 1 \times 1$ \\
6.5 & 7.5 & 1.0 & 0 & 0 & 0.390625 & $1 \times 1 \times 1$ \\
9.5 & 7.5 & 1.0 & 90 & $*$ & 0.390625 & $1 \times 1 \times 1$ \\
\hline
\end{tabular}

${ }^{1}$ Because the inclination is vertical, the declination can take on any value.

A Helbig-Euler inversion on the vector components without any inducing field was able to recover the locations and magnetizations of nine equivalent dipole sources (table 10). The 
equivalent dipole sources for the vertically oriented plates are relatively shallow, and those for the horizontally oriented plates are relatively deep.

Table 10. Results of Helbig-Euler inversion on the plate model without any inducing field.

$\left[\mathrm{A}-\mathrm{m}^{2}\right.$, ampere $\mathrm{x}$ meter $\left.^{2}\right]$

\begin{tabular}{ccccccc}
\hline $\begin{array}{c}\text { Easting } \\
\text { (meters) }\end{array}$ & $\begin{array}{c}\text { Northing } \\
\text { (meters) }\end{array}$ & $\begin{array}{c}\text { Depth } \\
\text { (meters) }\end{array}$ & $\begin{array}{c}\text { Inclination } \\
\text { (degrees) }\end{array}$ & $\begin{array}{c}\text { Declination } \\
\text { (degrees) }\end{array}$ & $\begin{array}{c}\text { Moment } \\
(\text { A-m })\end{array}$ & Aspect \\
\hline 3.5 & 2.5 & 0.7774 & 0.0676 & 89.981 & 0.2970 & $1 \times 5 \times 5$ \\
6.5 & 2.5 & 0.7160 & -0.5427 & 0.247 & 0.2464 & $5 \times 1 \times 5$ \\
9.5 & 2.5 & 1.5571 & 89.8123 & -33.665 & 0.7114 & $5 \times 5 \times 1$ \\
3.5 & 5.0 & 0.9792 & -0.0449 & 90.001 & 0.4386 & $1 \times 3 \times 3$ \\
6.5 & 5.0 & 0.7851 & 0.1167 & 0.354 & 0.2597 & $3 \times 1 \times 3$ \\
9.5 & 5.0 & 1.1787 & 89.6944 & 171.477 & 0.5159 & $3 \times 3 \times 1$ \\
3.5 & 7.5 & 1.0852 & -0.0978 & 89.981 & 0.4616 & $1 \times 1 \times 1$ \\
6.5 & 7.5 & 0.8737 & 0.9159 & 0.091 & 0.2781 & $1 \times 1 \times 1$ \\
9.5 & 7.5 & 0.9900 & 89.4207 & 170.582 & 0.3841 & $1 \times 1 \times 1$ \\
\hline
\end{tabular}

To simulate the peak response of the active system, a vertical inducing field was applied to the model under the assumption that all sources had a Koenigsberger ratio of 1.0. Table 11 shows the results of a Helbig-Euler inversion on the vector components with the inducing field in the downward direction, and table 12 shows the results on the vector components with the inducing field in the upward direction. Note that the upward-inducing field exactly cancels the field of the three source bodies with vertical remanent magnetization.

Table 11. Results of Helbig-Euler inversion on the plate model with downward-inducing field. $\left[\mathrm{A}-\mathrm{m}^{2}\right.$, ampere $\mathrm{x}$ meter $\left.^{2}\right]$

\begin{tabular}{ccccccc}
\hline $\begin{array}{c}\text { Easting } \\
\text { (meters) }\end{array}$ & $\begin{array}{c}\text { Northing } \\
\text { (meters) }\end{array}$ & $\begin{array}{c}\text { Depth } \\
\text { (meters) }\end{array}$ & $\begin{array}{c}\text { Inclination } \\
\text { (degrees) }\end{array}$ & $\begin{array}{c}\text { Declination } \\
\text { (degrees) }\end{array}$ & $\begin{array}{c}\text { Moment } \\
\left(\text { A-m }{ }^{2}\right)\end{array}$ & Aspect \\
\hline 3.5 & 2.5 & 0.7397 & 41.73358 & 88.813 & 0.3548 & $1 \times 5 \times 5$ \\
6.5 & 2.5 & 0.6718 & 40.81954 & 1.440 & 0.2886 & $5 \times 1 \times 5$ \\
9.5 & 2.5 & 1.4978 & 89.33935 & -13.967 & 1.2983 & $5 \times 5 \times 1$ \\
3.5 & 5.0 & 0.9209 & 43.15523 & 90.048 & 0.5359 & $1 \times 3 \times 3$ \\
6.5 & 5.0 & 0.7983 & 43.21744 & 1.092 & 0.3884 & $3 \times 1 \times 3$ \\
9.5 & 5.0 & 1.1664 & 89.68020 & -153.122 & 0.9993 & $3 \times 3 \times 1$ \\
3.5 & 7.5 & 1.0118 & 45.04357 & 90.955 & 0.5629 & $1 \times 1 \times 1$ \\
6.5 & 7.5 & 0.9802 & 45.61699 & 0.242 & 0.5141 & $1 \times 1 \times 1$ \\
9.5 & 7.5 & 0.9814 & 89.49455 & 178.788 & 0.7479 & $1 \times 1 \times 1$ \\
\hline
\end{tabular}


Table 12. Results of Helbig-Euler inversion on the plate model with upward-inducing field. $\left[\mathrm{A}-\mathrm{m}^{2}\right.$, ampere $\mathrm{x}$ meter $\left.^{2}\right]$

\begin{tabular}{ccccccc}
\hline $\begin{array}{c}\text { Easting } \\
\text { (meters) }\end{array}$ & $\begin{array}{c}\text { Northing } \\
\text { (meters) }\end{array}$ & $\begin{array}{c}\text { Depth } \\
\text { (meters) }\end{array}$ & $\begin{array}{c}\text { Inclination } \\
\text { (degrees) }\end{array}$ & $\begin{array}{c}\text { Declination } \\
\text { (degrees) }\end{array}$ & $\begin{array}{c}\text { Moment } \\
\left(\mathrm{A}-\mathrm{m}^{2}\right)\end{array}$ & Aspect \\
\hline 3.5 & 2.5 & 0.8002 & -39.9867 & 91.77386 & 0.4271 & $1 \times 5 \times 5$ \\
6.5 & 2.5 & 0.7629 & -40.0210 & .46948 & 0.3815 & $5 \times 1 \times 5$ \\
9.5 & 2.5 & $* 1$ & $*$ & $*$ & $*$ & $5 \times 5 \times 1$ \\
3.5 & 5.0 & 1.0229 & -44.7400 & 88.68530 & 0.6514 & $1 \times 3 \times 3$ \\
6.5 & 5.0 & 0.8054 & -44.0549 & 1.61406 & 0.3927 & $3 \times 1 \times 3$ \\
9.5 & 5.0 & $*$ & $*$ & $*$ & $*$ & $3 \times 3 \times 1$ \\
3.5 & 7.5 & 1.1291 & -45.6148 & 88.01538 & 0.6914 & $1 \times 1 \times 1$ \\
6.5 & 7.5 & 0.7994 & -42.7912 & 1.14784 & 0.3404 & $1 \times 1 \times 1$ \\
9.5 & 7.5 & $*$ & $*$ & $*$ & $*$ & $1 \times 1 \times 1$ \\
\hline
\end{tabular}

${ }^{1}$ No values because the inducing field exactly cancels the remanent field.

Table 13. Estimated magnetic susceptibilities and Koenigsberger ratios for the plate model. [Q, Koenigsberger ratio; Susc., magnetic susceptibility]

\begin{tabular}{cccccccc}
\hline \multirow{2}{*}{$\begin{array}{c}\text { Easting } \\
\text { (meters) }\end{array}$} & $\begin{array}{c}\text { Northing } \\
\text { (meters) }\end{array}$ & \multicolumn{2}{c}{ Downward field } & \multicolumn{2}{c}{ Upward field } & \multicolumn{2}{c}{ Average } \\
\cline { 3 - 7 } & Susc. & $\mathbf{Q}$ & Susc. & $\mathbf{Q}$ & Susc. & $\mathbf{Q}$ \\
\hline 3.5 & 2.5 & 0.235834 & 1.259416 & 0.274829 & 1.080720 & 0.255332 & 1.170068 \\
6.5 & 2.5 & 0.190986 & 1.290113 & 0.242988 & 1.014017 & 0.216987 & 1.152065 \\
9.5 & 2.5 & 0.586830 & 1.212255 & 0.586830 & 1.212255 & 0.586830 & 1.212255 \\
3.5 & 5.0 & 0.366857 & 1.195554 & 0.458147 & 0.957328 & 0.412502 & 1.076441 \\
6.5 & 5.0 & 0.265441 & 0.978384 & 0.273612 & 0.949164 & 0.269527 & 0.963774 \\
9.5 & 5.0 & 0.483386 & 1.067227 & 0.483386 & 1.067227 & 0.483386 & 1.067227 \\
3.5 & 7.5 & 0.399088 & 1.156531 & 0.493355 & 0.935549 & 0.446222 & 1.046040 \\
6.5 & 7.5 & 0.363011 & 0.766083 & 0.235662 & 0.935549 & 0.299337 & 0.850816 \\
9.5 & 7.5 & 0.363787 & 1.055894 & 0.363787 & 1.055894 & 0.363787 & 1.055894 \\
\hline
\end{tabular}

Again the estimated susceptibilities are close to the true susceptibilities of 0.39 to 0.42 , and the estimated $Q$ values are all close to the true value of 1.0. There is no apparent way to distinguish between the small cube-like bodies that approximate true dipoles and the plate-like sources.

\section{Engineering Assessment}

A conceptual block diagram for the ATMGS is shown in figure 15. Components unique to the ATMGS are the Primary Drive Coil and the Active Drive Unit, which contains the Oscillator Circuitry and the Drive Current Circuitry. The drive current circuit has links to the magnetometer control circuitry for feedback control, and to the sample and hold in the data acquisition unit for monitoring of the primary drive current. The engineering assessment focused on the hardware requirements for the active drive unit and the primary drive coil. 


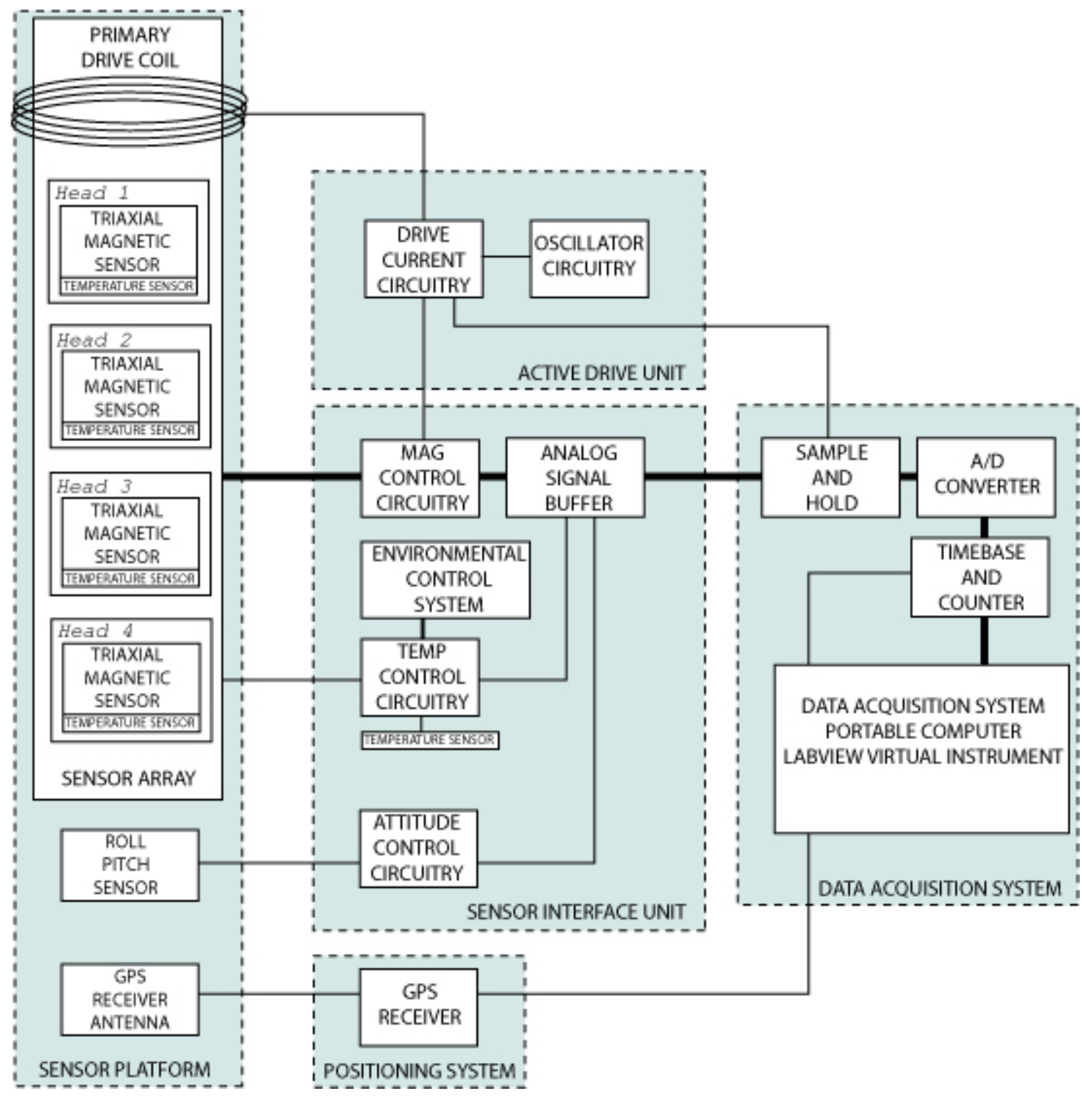

Figure 15. Conceptual block diagram of the Active Tensor Magnetic Gradiometer System (ATMGS).

\section{Primary Signal Generator}

The object of this task was to design and specify an active constant current drive signal for the ATMGS. The requirements for the system are as follows: the system generates a constant amplitude sine wave magnetic signal of less than $100 \mathrm{~Hz}$, the amplitude being at least 12 amperes (A) peak (8.5 A root-mean-squared); the amplitude should remain as constant as possible over a varying temperature range, with minimum distortion; and the coil should fit the existing TMGS cart. In the event this last requirement changes, the calculations can be repeated for different coil geometries. A conceptual block diagram of the active drive unit is given in figure 16. 


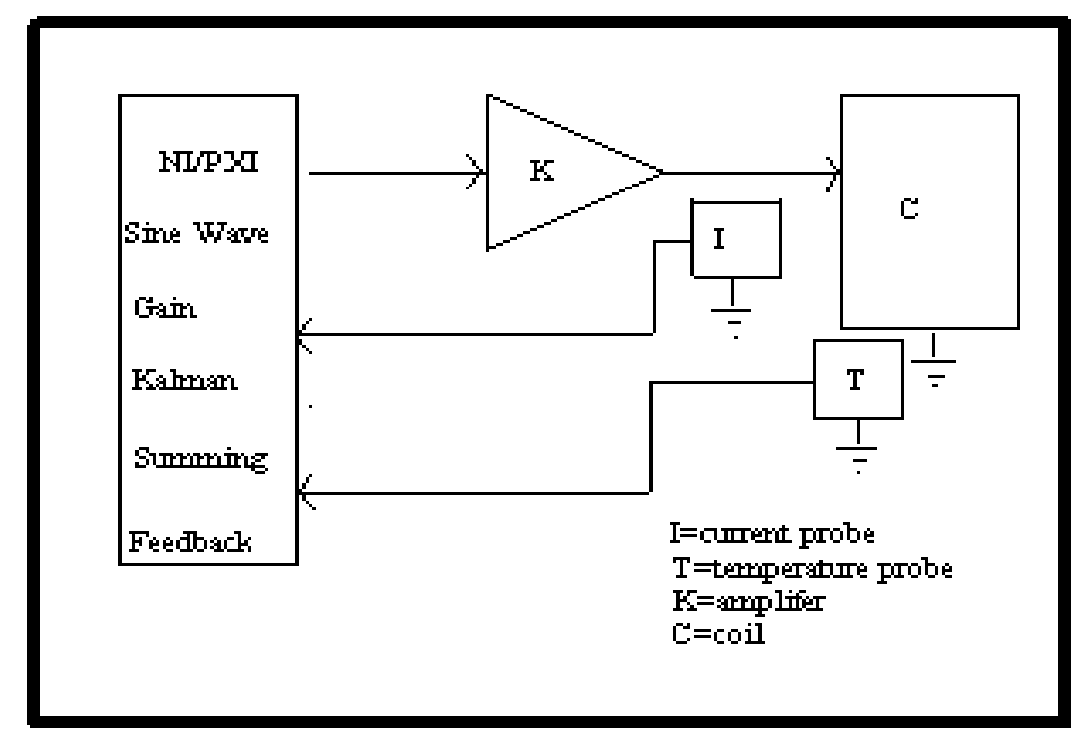

Figure 16. Conceptual block diagram of the active drive unit. Functions controlled by the control unit are listed in the NI/PXI box. Subsystems are labeled NI/PXI, K, I, C, and T.

To achieve the design objective, the following specifications were developed for each subsystem.

\section{Coil Parameters (C)}

For this analysis a square coil having 45 inches $(1.143 \mathrm{~m})$ on a side with a 20-turn tight winding is assumed. If a \#10 gauge copper wire is used, the coil will have a resistance of approximately $0.3 \mathrm{ohm}(\Omega)$ at 20 degrees Celsius $\left({ }^{\circ} \mathrm{C}\right)$. The resistance would increase to approximately $0.38 \Omega$ at $60^{\circ} \mathrm{C}$. Using an inductance calculator, such as the one available on-line at (http://www.cvel.clemson.edu/emc/calculators/Inductance_Calculator/square.html), the inductance of the coil would be 2.95 millihenry $(\mathrm{mH})$, giving a reactance of $1.22 \Omega$ at $100 \mathrm{~Hz}$. Therefore, the total worst case impedance would be approximately $1.6 \Omega$ at $60^{\circ} \mathrm{C}$ and $100 \mathrm{~Hz}$ signal input. This coil design would deliver a peak moment magnitude of $15.68 \mathrm{~A}-\mathrm{m}^{2}$.

\section{Amplifier Specifications (K)}

A standard class AB audio power amplifier can be used to drive the coil. A typical 4-ohm speaker has a dc (direct current) resistance of $3.3 \Omega$ and an inductance of 2-5 $\mathrm{mH}$. The minimum impedance rating for most audio amplifiers is $4 \Omega$. Therefore, a noninductive series resistor of approximately $1.7 \Omega$ would be added to increase the overall load to $4 \Omega$, or $0.4 \Omega$ for a $2 \Omega$ load. With a $4 \Omega$ load, the amplifier would have to provide 289 watts (W) of continuous power. Using the conventional two-times engineering margin, a $580-\mathrm{W}$ amplifier at a $4 \Omega$ load is sufficient. If a $2-\Omega$ load amplifier is available, the wattage would be reduced to $290 \mathrm{~W}$. A possible candidate is the Crown Micro-Tech 2400 Professional Power Amplifier, which can supply 1,050 W into a $2 \Omega$ load. 


\section{Current Sensor (I)}

A standard audio amplifier is a constant voltage device. To make it a constant current system, a voltage representing the output current is used as feedback. Of the current monitoring devices available, a magneto resistive device provides the best linearity, zero crossing linearity, isolation and temperature compensation. An example of such a device is the NT-15 from F.W. Bell. It states a linearity of less than 0.1 percent and a bandwidth of $100 \mathrm{kHz}$.

\section{Sine Wave Source}

The existing National Instruments (NI) PXI system (National Instruments web site www.ni.com/pxi/) can be used as a signal source for the sine wave. The NI system can also be used as the feedback point. This provides a flexible feedback system for possible improvement exploration, should that be necessary. The inaccuracy of the raw sine wave in Labview (NI's software development system) was measured at 5E-10 for a 1-volt output or 0.5 parts per billion (ppb). Using a 24-bit digital/analog converter (D/A) to output the signal produces an uncertainty of $6 \mathrm{E}-8$ or $60 \mathrm{ppb}$. A 16-bit D/A would be $1.5 \mathrm{E}-5$ or 15 parts per million (ppm).

\section{Temperature Control (T)}

Another factor requiring compensation would be the thermal expansion of the coil. With a possible increase of 0.13 percent in area over a $40^{\circ} \mathrm{C}$ temperature range, a feedback control to adjust the current to compensate for this is needed. A temperature probe providing feedback should accomplish this. The resolution of an existing probe is $0.1^{\circ} \mathrm{C}$. Over $40^{\circ} \mathrm{C}$, this would give a resolution of one part per 1,000. This implies a resolution of $1.3 \mathrm{E}-6$ or $1.3 \mathrm{ppm}$ temperature compensation.

\section{Possible Sources for Improvement (NI/PXI)}

The use of the NI/PXI package to develop the appropriate feedback gains and summing allows for the possible use of a Kalman filter to increase the accuracy of the current. A Kalman filter (Simon, 2003; Bishop, 2001; Cipra, 1993) provides increased accuracy in the presence of white (Gaussian) noise if the system is linear. Such is the case for this system.

For an active magnetic system, canceling the portion of the magnetic field from the primary drive coil would be necessary. For an ATMGS with the drive coil surrounding the magnetometer array, the field strengths and gradients at the sensors would be considerable, as illustrated in figure 17. 


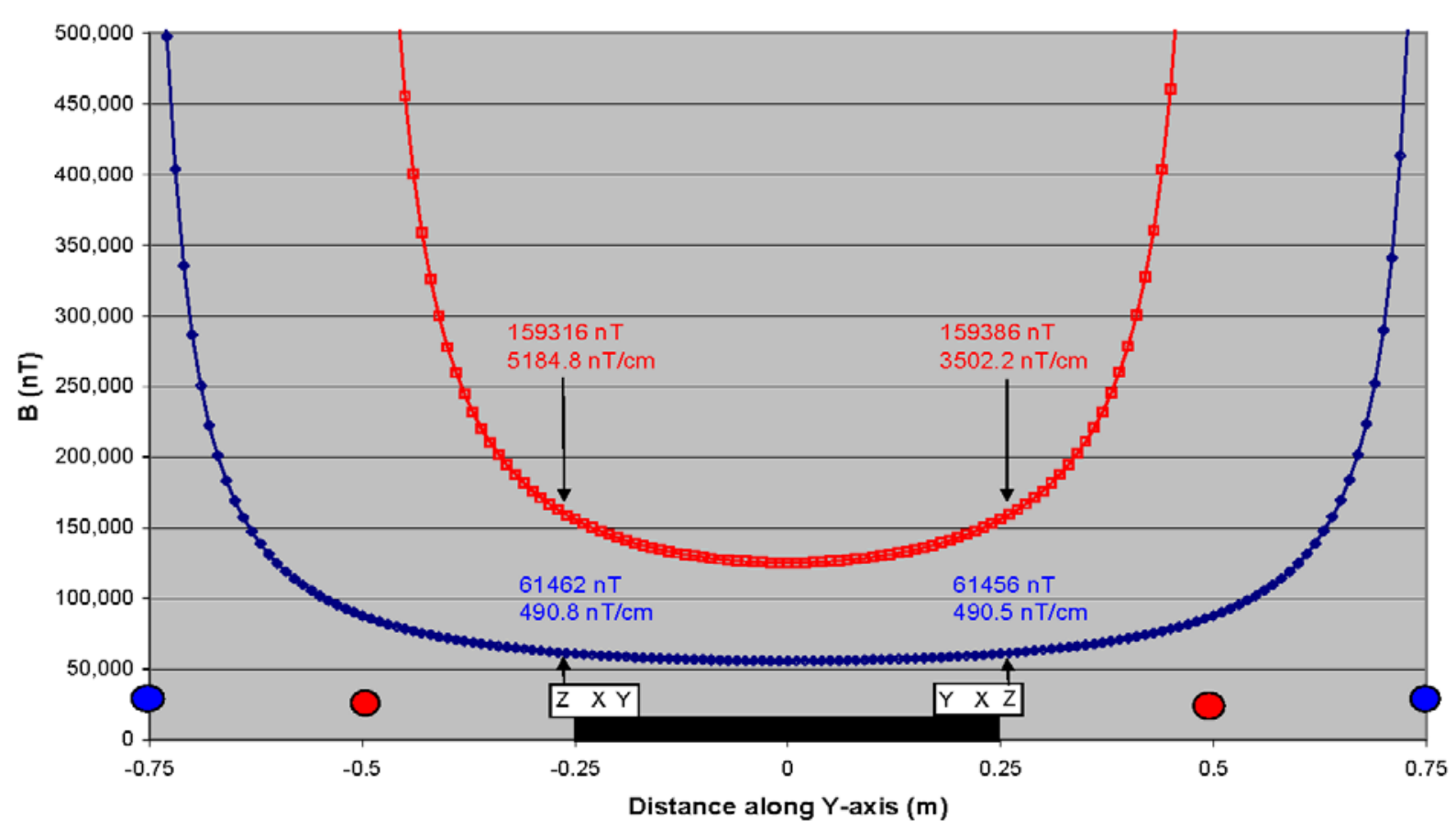

Figure 17. Primary coil field strength with distance in relation to the sensor array. The black rectangle represents the array baseplate; the white rectangles represent fluxgate heads. Magnetic field strength is plotted for a 1.0-m diameter coil (red) and a 1.5-m diameter coil (blue). Arrows point to the field strength and gradient at the location of the z-component fluxgate axes.

Three nulling methods are considered: numerical subtraction, a bucking coil, and use of the existing feedback coils contained in each ring core sensor.

\section{Numerical Subtraction}

From the design of the controlled sine wave generator, we would have an accurate measure of the drive current, hence an estimate of the field strength at the magnetometers. Using the field strength value and scaling it, we can get a value for the field at the magnetometer's heads. As long as this field is in the range of the existing fields (mainly the Earth's magnetic field), we can subtract it from the received signal. This method would be straightforward to implement in software or postprocessing, and success could be accurately determined through laboratory experiments. However, this method would be unable to compensate for unexpected changes in field strength or direction, such as those caused by misalignment of the primary coil and the sensor array. Mechanical deformations and misalignments are difficult to control during operation over real terrains. Just as the sensor array must be calibrated in a controlled magnetic environment, the primary coil/array interaction would need to be calibrated in a controlled setting. Because it is not known how the ring-core fluxgate sensors would perform in a harsh magnetic environment (high fields, high gradients, high slew rate), this method is probably not appropriate. 


\section{Bucking Coil}

A bucking coil would be a separate coil encompassing the entire magnetometer array and driven by a scaled, reversed value of the drive current so as to provide a magnetic well where the drive fields are neutralized. Several versions of this are possible. One would use the drive current with the coil wound in reverse and the number of turns adjusted to compensate for the difference in the area of the two coils. In principle this method is the best because it would be simple to implement electronically. Only one drive amplifier would be required, and there would be no additional software controls. On the other hand, this method would be difficult to implement mechanically -the sensor array, the primary field coil, and the bucking coil would have to be maintained in rigid alignment. It would be difficult to tune or adjust, and it would be difficult to wind an accurate, large bucking coil and position it so that all 12 magnetic axes are nearly nulled. Furthermore, the primary coil/bucking coil/array interaction would need to be calibrated in a controlled setting.

An alternative design would be to drive the bucking coil with another amplifier whose input signal is derived from the active drive unit. This would offer easy current adjustment with the possibility of adjusting the current dynamically. However, two amplifiers are required with more complexity in the electronics and software development. Mainly because of difficulties with fabrication and mechanical stability, neither of these methods is appropriate.

\section{Ring-Core Feedback}

A variation on the bucking coil would be to use existing ring core feedback circuits and insert bucking currents directly to each magnetic field sensor (Magnes and others, 2003). This scheme can provide current compensation to all 12 magnetic components without the need for a large external bucking coil. Individual bucking currents would be determined from empirical measurements (nulling tests) in a controlled magnetic environment. Offsetting the advantage this method offers is increased electronic complexity and the possibility that tapping into the feedback circuit of the existing interface electronics would create unforeseen problems. Because of its fundamental simplicity, this method is appropriate as the first approach.

\section{Alternative Sensor Technologies}

In evaluating alternative fluxgate magnetometers, a literature review led to the following technical papers deemed most relevant to our engineering evaluation:

- Advanced Composition Explorer (ACE) Magnetometer Instrument (MAG) (Bartol Research Institute, 1994),

- Development, construction and analysis of the 'Oersted' fluxgate magnetometer (Nielsen and others, 1995),

- Digital detection and feedback fluxgate magnetometer (Piil-Henriksen and others,1996),

- New kind of fluxgate magnetometer probe with enhanced electronic processing (Cruz and others, 1998),

- Fluxgate: Tuned vs. untuned output (Ripka, 1998),

- Portable fluxgate magnetometer (Ripka and Kaspar, 1998),

- Digital Fluxgate for the Astrid-2 satellite (Pedersen and Primdahl, 1999),

- Ring-core flux-gate magnetometer with microprocessor (Kilić and others, 1999),

- Magnetic field measurements in space: The NewMag Magnetometer (Bish and others, 2000),

- Crossfield effect at fluxgate (Ripka and Billingsley, 2000), 
- Comparison of two digital fluxgate magnetometers developed for space application (Magnes and Auster, 2001),

- A digital fluxgate magnetic sensor interface using sigma-delta modulation for weak magnetic field measurements (Kawahito and others, 2002),

- The fluxgate ring-core internal field (Primdahl and others, 2002), and

- A sigma-delta fluxgate magnetometer for space applications (Magnes and others, 2003).

A miniaturized ATMGS is proposed based upon existing equipment and state-of-the-art practices described in the listed articles. The system would consist of the existing Narod triaxial fluxgate heads and cables, a 24-bit analog-to-digital converter (A/D), a digital signal processor (DSP), a 24-bit digital-to-analog converter (D/A) for the primary drive waveform and bucking-coil current feedback, and a wireless communication system to receive commands and send data to a remote computer.

Commercial 24-bit A/D and D/A units are widely available and cost effective. They can provide flexibility in determining the maximum quantization necessary from the input and feedback signal. They are capable of $200 \mathrm{kHz}$ sample rates, should that be necessary. If time and resources permit, the fluxgate interface electronics would be enhanced using one of the methods mentioned in the articles. A digital signal processor (DSP) can be programmed from a Labview software program. This provides quick turn-around during development. It also provides an ability to try various methods of signal extraction. For example, all even harmonics or just the second harmonic, use of a finite impulse response (FIR) filter to cancel all odd harmonics or an analog bandpass filter or both, using a fast Fourier transform to analyze the received signal, use of a binning technique for feedback control, direct read-out without feedback, and adjustable bandwidth. The unit could be set up to transmit the data wirelessly to a remote station using one of the current technologies such as Bluetooth, Wi-Fi, or ZigBee. ZigBee might not handle the data volume required, but it would provide built-in data collision prevention from many sources.

Other sensor types evaluated, and comments, follow:

- Proton and Overhauser magnetometers are scalar instruments, heavy, high power; satellite Overhauser weighs 1 kilogram $(\mathrm{kg})$ and requires $3 \mathrm{~W}$ of power.

- High temperature Superconducting Quantum Interference Devices (SQUID) have lower noise but require liquid nitrogen.

- Hall sensors are noisy and have temperature-dependent offsets.

- Magnetodiodes and magnetoresistors perform no better than Hall sensors of the same size.

- GMI (Giant Magnetoresistors and Giant Magnetoinductance) effects are weak and impractical.

- GMR (Giant Magnetoresistor) has parabolic characteristics and 4 percent hysteresis and nonlinearity, expensive electronic compensation is required.

- AMR (Anisotropic Magnetoresistors) work well in the flipping mode, but have high noise.

On the basis of the foregoing evaluation of current magnetic sensor technology, keeping the Narod Geophysics triaxial ring-core fluxgates in the ATMGS design is most appropriate at this time.

\section{Summary}

An interactive computer program was developed to simulate a conceptual active tensor magnetic gradiometer system (ATMGS). The ATMGS simulator incorporates physical models of system sensors, platform geometry, Earth environment, and spheroidal magnetically-permeable targets. Numerical simulations of realistic UXO survey scenarios show that it is possible to invert 
ATMGS data to a spheroidal model closely approximating the source. To investigate whether an ATMGS system can separate induced components of magnetization from remanent components, Helbig-Euler simulations were run with rectangular and rod-like source bodies. Analysis of these simulation data show that there is no apparent way to distinguish between the small cube-like bodies that approximate true dipoles and plate-like and rod-like sources.

\section{References Cited}

Altshuler, T.W., 1996, Shape and orientation effects on magnetic signature prediction for unexploded ordnance: Proceedings of the UXO forum '96, Williamsburg, Va., p. 282-291.

Bartol Research Institute, 1994, Advanced Composition Explorer (ACE) Magnetometer Instrument (MAG) Instrument Functional Requirement Document (IFRD): Newark, Del., University of Delaware.

Billings, S.D., 2002, UXO discrimination and identification using magnetometry: Proceedings of the Society for the Application of Geophysics to Engineering and Environmental Problems (SAGEEP), Las Vegas, Nev.

Bish A., Fraser, B.J., Menk, F.W., Waters, C.L., Means, J.D., and Russell, C.T., 2000, Magnetic field measurements in space - The NewMag Magnetometer: Proceedings of the Workshop on Applications of Radio Science (WARS'00), p. 160-169.

Bishop, G., 2001, An introduction to the Kalman filter: SIGGRAPH 2001 Course 8, Association for Computing Machinery, Inc., SIGGRAPH 2001, Los Angeles, Calif.

Butler, D.K., 2001, Potential fields methods for location of unexploded ordnance (UXO): The Leading Edge, August 2001, 6 p.

Cipra, B., 1993, Engineers look to Kalman filtering for guidance: Society for Industrial and Applied Mathematics (SIAM) News, v. 26, no. 5.

Cruz, J.C., Trujillo, H., and Rivero, M., 1998, New kind of fluxgate magnetometer probe with enhanced electronic processing: Sensors and Actuators, A: Physical, v. 71, no.3, p. 167-171.

Grover, F.W., "Inductance Calculations", http:// emclab.mst.edu/inductance/index.html [accessed on Dec. 21, 2007]

Helbig, K., 1963, Some integrals of magnetic anomalies and their relation to the parameters of the disturbing body: Zeitschrift für Geophysik, v. 29, no.2, p. 83-96.

Kawahito, S., Cerman, A., and Tadokoro, Y., 2002, A digital fluxgate magnetic sensor interface using sigma-delta modulation for weak magnetic field measurements: Instrumentation and Measurement Technology Conference, Proceedings of the 19th IEEE, p. 257-260.

Kilić, T., Boršić, M., and Milun, S., 1999, Ring-core flux-gate magnetometer with microprocessor: Measurement - Journal of the International Measurement Confederation, v. 25, no. 1, p. 47-51.

Magnes, W., and Auster, H., 2001, Comparison of two digital fluxgate magnetometers developed for space application: Contributions to Geophysics and Geodesy, v. 31, p. 67-74.

Magnes, W., Pierce, D., Valavanoglou, A., Means, J., Baumjohann, W., Russell, C.T., Schwingenschuh, K., and Graber, G., 2003, A sigma-delta fluxgate magnetometer for space applications: Measurement Science and Technology, v. 14, p. 1003-1012.

National Instruments, http://www.ni.com/pdf/products/us/pxi4461.pdf [accessed on Dec. 21, 2007]

Nielsen, O.V., Petersen, J.R., Primdahl, F., Brauer, P., Hernando, B., Fernandez, A., Merayo, J.M.G., and Ripka, P., 1995, Development, construction and analysis of the 'Orsted' fluxgate magnetometer: Measurement Science and Technology, v. 6, no. 8, p. 1099-1115.

Pedersen, E.B., and Primdahl, F., 1999, Digital fluxgate magnetometer for the Astrid-2 satellite: Measurement Science and Technology, v. 10, p. N124-N129. 
Phillips, J.D., 2005, Can we estimate total magnetization directions from aeromagnetic data using Helbig's integrals?: Earth, Planets and Space, v. 57, no.8, p. 681-689.

Phillips, J.D., Nabighian, M.N., Smith, D.V., and Li, Y., 2007, Estimating locations and total magnetization vectors of compact magnetic sources from scalar, vector, or tensor magnetic measurements through combined Helbig and Euler analysis: Society of Exploration Geophysics Expanded Abstracts v. 26, p. 770.

Piil-Henriksen, J., Merayo, J.M.G., Nielsen, O.V., Petersen, H., Raagaard Petersen, J., and Primdahl, F., 1996, Digital detection and feedback fluxgate magnetometer: Measurement Science and Technology, v. 7, p. 897-903.

Primdahl, F., Brauer, P., Merayo, J.M.G., and Nielsen, O.V., 2002, The fluxgate ring-core internal field. Measurement Science and Technology, v. 13, no.8, p. 1248-1258.

Reid, A.B., Allsop, J.M., Granser, H., Millett, A.J., and Somerton, I.W., 1990, Magnetic interpretation in three dimensions using Euler deconvolution: Geophysics, v. 55, p. 80-91.

Ripka, P., 1998, Fluxgate - Tuned vs. untuned output: IEEE Transactions on Magnetics, v. 34, no. 4 part 1, p. 1303-1305.

Ripka, P., and Kaspar, P., 1998, Portable fluxgate magnetometer: Sensors and Actuators APhysical, v. 68, nos. 1-3, p. 286-289.

Ripka, P., and Billingsley, S.W., 2000, Crossfield effect at fluxgate: Sensors and Actuators APhysical, v. 81, no. 1, p. 176-179.

Schmidt, P.W., and Clark, D.A. 1997, Directions of magnetization and vector anomalies derived from total field surveys: Australian Society of Exploration Geophysicists Preview, v. 70, p. 3032.

Schmidt, P.W. and Clark, D.A., 1998, The calculation of magnetic components and moments from TMI - A case history from the Tuckers igneous complex: Queensland, Exploration Geophysics, v. 29, p. 609-614.

Simon, D., 2003, Kalman filtering for fuzzy discrete time dynamic systems: Applied Soft Computing, v. 3 (2003), p. 191-207.

Zhang, C., Mushayandebvu, M.F., Reid, A.B., Fairhead, J.D., and Odegard, M.E., 2000, Euler deconvolution of gravity tensor gradient data: Geophysics, v. 65, p. 512-520. 